\title{
Is Education Now Class Destiny? Class Histories across Three British Birth Cohorts
}

\author{
Erzsébet Bukodi \\ Department of Social Policy and Intervention and Nuffield College \\ University of Oxford \\ erzsebet.bukodi@spi.ox.ac.uk \\ John H. Goldthorpe \\ Nuffield College \\ University of Oxford \\ john.goldthorpe@nuffield.ox.ac.uk \\ Brendan Halpin \\ Department of Sociology \\ University of Limerick \\ brendan.halpin@ul.ie \\ Lorraine Waller \\ Department of Social Policy and Intervention \\ University of Oxford \\ lorrainewallerpearson@gmail.com
}

Accepted for publication in European Sociological Review. 


\title{
Is Education Now Class Destiny? Class Histories across Three British Birth Cohorts
}

\begin{abstract}
We investigate claims originating in the work of Daniel Bell that in post-industrial societies educational qualifications obtained prior to labour market entry increasingly determine individuals' class positions - while opportunities for achieving upward class mobility over the course of working life correspondingly diminish. We apply optimal matching techniques of sequence analysis as a basis for constructing typologies of class histories for men and women in three British birth cohorts whose lives span the period from the mid-twentieth to the early twenty-first century. We find a steady increase across the cohorts in class histories characterised by entry into, and stability within, managerial and professional positions and associated with relatively high levels of qualification. However, there is no decline in class histories characterised by upward mobility; and, while there are clear associations between education and most of the types of class history that we distinguish, the effects of education are systematically and persistently reinforced, or modified, by the independent effects of early life cognitive ability and of class origins. In Britain at least, there is little indication of movement towards an education-based meritocracy, and educational level at labour market entry is today no more class destiny than it was half-a-century ago.
\end{abstract}




\section{Introduction}

Daniel Bell (1973: 14, see also 18-26 and ch. 3) saw the centrality of theoretical knowledge' as the 'axial principle' of modern, post-industrial society. A far-reaching consequence, he then argued, had to be recognised. Educational institutions, as the disseminators of theoretical knowledge and of associated expertise and skills, assume a dominant role in the allocation of individuals to different positions within the division of labour. In particular, the university, 'which once merely reflected the status system of the society', becomes 'the arbiter of class position' and 'gains quasimonopoly power over the fate of individuals'. The post-industrial society is 'in its logic' an education-based meritocracy: a new social order is emerging 'based, in principle, on the priority of educated talent' (1972: 30-1, 41). An advantaged social background can no longer, in itself, guarantee access to 'high places'; these will lie beyond the reach of men and women of whatever background who lack appropriate qualifications. Moreover, while opportunities for individuals to achieve upward class mobility in the course of their working lives on the basis simply of their native ability and work experience were once extensive, with 'modernisation' these opportunities must contract. In the context of rapid scientific and technological advance, ability and 'empirical knowledge' alone are insufficient. And this is the case, Bell argues, not only in the professions and technical occupations; now in management and administration also individuals are 'rarely promoted from below but are chosen from the outside' - with a university degree being the 'passport of recognition' (1972: 30; 1973: 410). In sum, it could be forecast that in post-industrial 
society qualifications obtained prior to entry into the world of work will progressively become 'class destiny'.

Views of the kind advanced by Bell have a continuing importance if only in view of their wide acceptance as in effect the 'conventional wisdom' of present-day political and public discourse. References to 'the knowledge economy' are frequent; prior educational attainment is believed to be ever-more important for entry into all levels of employment except the most disadvantaged; and across the party political spectrum policies of educational expansion and reform are regarded as vital both in enhancing national economic performance and in maintaining or raising levels of social mobility (see e.g. the annual OECD reports Economic Policy Reform: Going for Growth and especially 2010, Part II, ch. 5).

Moreover, Bell's work itself has remained a crucial reference point in contemporary sociology. While some investigators have produced evidence at least in part supportive of Bell's position (e.g. Gershuny, 1993) a more questioning response has been more common. Thus, Breen and Luijkx (2004: 394), taking Bell's work as 'the most fully elaborated' view of the increasingly dominant role of education in determining class positions, observe that this is scarcely consistent with results from comparative research that point to decreasing 'class returns' to education. Likewise, Barone and Schizzerotto (2011), in a critical commentary on Bell and modernisation theory, find no evidence from comparative research that the association between individuals' education and their first occupation on labour market entry is 
strengthening. And, most recently, Ballarino and Bernardi (2016), beginning explicitly with Bell's claim that position in the labour market is becoming exclusively dependent on educational attainment, see this as contradicted in that across a range of advanced societies the 'direct' association between individuals' socioeconomic origins and destinations - i.e. that not mediated through education - shows little weakening.

Our own research focuses on these same issues, which would appear central to the understanding of contemporary social stratification. However, we aim to complement work of the kind cited above in the following way. Since it is crucial to Bell's argument that upward mobility into high level class positions achieved over the course of working life will decline, it is necessary, in order to test this claim directly, to take a 'biographical' rather than a 'transversal' perspective on mobility (cf. Bertaux, 1974; Bühlmann, 2010) and this we aim to do. Specifically, we address the two following research questions.

1) Is there evidence that the detailed trajectories of individuals' class histories are changing over time in that greater stability is apparent from labour market entry onwards and, in particular, in that upward class mobility subsequent to labour market entry is a declining feature of these trajectories?

2) Is there corresponding evidence of the emergence of an education-based meritocracy in that educational attainment prior to labour market entry is becoming 
more closely associated with the trajectories of individuals' class histories, while the association of these trajectories with, on the one hand, their class origins and, on the other hand, their basic cognitive ability, in both cases considered independently of their educational attainment, is being reduced?

In studying the progression of individuals' life-courses, several different approaches are possible. In view of the nature of the research questions that we pursue, we opt for sequence analysis via optimal matching (OM) (Abbott and Tsay, 2000; MacIndoe and Abbott, 2004) rather than for some more conventional statistical method. As against methods that entail the decomposition of the life-course into particular states or events and focus on their relative timing, as, say, through event history analysis, sequence analysis via optimal matching, aims to capture some aspect of the lifecourse in its totality (Halpin and Chan, 1998; Billari, 2005) - in our case, class histories. Further, as against other similarly 'holistic' approaches, such as latent class analysis, OM is better able to take direct account of longitudinality (Barban and Billari, 2012), which in our case is crucial since it is with the actual sequence of states in class histories that we are concerned. And finally as against latent growth curve analysis, which may be attractive where the outcome variable can be measured on some continuous scale, OM can operate with discrete categories, which is important to us since, for reasons presented elsewhere (Bukodi, Dex and Goldthorpe, 2011), we see serious disadvantages in treating social stratification in terms of scales of, say, social distance or socio-economic status. 
The empirical analyses we present relate to the British case which we believe has strategic value, given our purposes. Britain was the first industrial nation and already by the earlier twentieth century its agricultural sector had shrunk to almost negligible proportions - in contrast, say, with countries such as France. But in the later twentieth century Britain experienced rapid deindustrialisation in the course of which its manufacturing sector declined to a far greater extent than in countries such as Germany, while the services sector became dominant. At the same time, a significant growth in higher education occurred, with one phase of expansion in the 1960s being followed by a second in the 1990s. Finally, the endogenous class mobility regime in Britain has been shown to have a high degree of stability over time (Bukodi et al., 2015), which has the advantage that there is then little danger of the specific issues that we are concerned with in the present paper being confounded with general changes in the level of social fluidity within the class structure.

Britain does then appear as a post-industrial society that provides a highly appropriate context for the further examination of Bell's seminal ideas on the emerging form of stratification of such societies; and it is certainly one in which these ideas are firmly embedded in policy analysis and formation (see e.g. HM Government, 2009, 2011). It is also relevant to note that for treating the particular research questions that we have posed in a life-course perspective, Britain can claim to have uniquely valuable datasets. 


\section{Data and variables}

We use data from the three earliest of the long-established series of British birth cohort studies: those covering children born in one week in 1946, 1958 and 1970 (for details, see Wadsworth et al., 2006; Power and Elliott, 2006; Elliott and Shepherd, 2006).

Drawing on these studies, it has been possible for us to establish for the majority of cohort members continuous class histories, in person-month form, that extend from their first 'significant' job - i.e. one lasting at least six months - up to age 38. This is the latest age for which we have relevant information for members of the 1970 cohort. However, by this age a stage of 'occupational maturity' is typically reached after which the probability of occupational change of a kind that would imply class mobility sharply falls (Bukodi and Goldthorpe, 2009). We allocate individuals to class positions according to the 7-category version of the UK National Statistics Socio-Economic Classification (NS-SEC), as shown in Table 1, following procedures reported in our previous research (Bukodi et al., 2015).

\section{[Table 1 here]}

Exploratory work led us to base individuals' class histories on the modal class - i.e. the class in which they spent most time - in each year of their working lives. In this way, short-run instabilities in class position are discounted while the main features of class trajectories are preserved. 
Also included in our analyses are the three following variables.

Educational qualifications at labour market entry. For members of the 1958 and 1970 cohorts we are able to construct their detailed educational histories up to age 38 . On this basis we can determine the highest level of qualification they had attained at the time of their labour market entry (first significant job). For members of the 1946 cohort, the information we have available is more limited and in their case we have to take as proxy their highest level of qualification at age 26. Any resulting overestimation of this level is likely to be slight, given that at this age around threefifths of the cohort still had no more than low-performance secondary qualifications. We treat educational qualifications in relative terms: i.e. we suppose that what chiefly matters, regarding labour market returns to education, is not how much education individuals have achieved in absolute terms but rather how much relative to those others with whom they are in most direct labour market competition. Based on our previous research (Bukodi and Goldthorpe, 2016) we know, at least for men, that if educational qualifications are measured absolutely, declining class returns to education show up across our cohorts, consistently with the findings of Breen and Luijkx (2004) previously referred to. If, however, qualifications are measured relatively, no trend is apparent. All else apart, it would therefore appear fairest in questioning Bell's position to use a relative measure. Full details of the construction of our variable of relative education at labour market entry are given in Online Appendix 1. 
Class origins. We index cohort members' class origins by their father's social class at age 11 for members of the 1946 and 1958 cohorts and at age 10 for members of the 1970 cohort. Where this information is missing but is available at age 15, for 1946 cohort members, or at age 16, for 1958 and 1970 cohort members, we use this alternative information. To preserve adequate counts, father's class is treated according to a collapsed 4-class version of NS-SEC (see Tables 7 and 8).

Early-life cognitive ability. Our measure of early-life cognitive ability comes from first principal component scores derived from the results of the verbal and non-verbal tests that were administered to members of all three cohorts at age 10 or 11 (Schoon, 2010). In regard to these scores, we again take a relative rather than an absolute view, in particular to allow for 'Flynn effects' (Flynn, 1987): i.e. we allocate cohort members to cohort-specific cognitive ability quintiles.

\section{The optimal matching of class histories: states and the costing of}

\section{differences}

In our application of sequence analysis via $\mathrm{OM}$, what is essentially involved is the systematic pairwise comparison, in terms of their degree of similarity or dissimilarity, of the sequences of 'states' forming the class histories of the members of the three birth cohorts that we consider. We work, as earlier noted, with individuals' modal class in each year of their employment up to age 38. The basic 
states of our sequences are therefore the seven NS-SEC classes. But, in addition, we introduce two further states: that of 'class not known' - i.e. for years in which information on the class position of a cohort member who has entered employment is missing - and that of 'pre-employment' which covers the period from age 16 to year of labour market entry. An advantage of including this latter state is that it results in all sequences being of the same length - i.e. each comprises 22 yearly states. Preliminary analyses indicated that where sequences are of unequal length, differences in length alone take on undue weight in the matching process. A number of other states could have been included, such as being unemployed or absent from the labour market for various reasons, but the relevance of these to the particular research questions being addressed appeared insufficient to warrant the additional complexity in the analysis that would have been involved ${ }^{1}$.

We leave out of our analyses cohort members for whom we have no information at all on their class positions - mainly individuals who have never been in employment; those for whom we have no information on their class position for a spell of over ten years (up to this point they are allocated to their most recent class); and also those whose first significant job occurred only after age 30.

In Table 2, we show the extent to which cases are in these ways lost. It can be seen that with the 1970 cohort study, which was from the start envisaged as a continuing one, the proportion of lost cases is quite small. In contrast, with the two earlier cohorts losses are clearly greater. It does, however, appear that this is in large part 
the result of operational shortcomings in data collection and coding procedures rather than of non-response, and, insofar as this is so, any bias may be minimised (Nathan, 1999). ${ }^{2}$

\section{[Table 2 here]}

We have then, as is also shown in Table 2, class histories for a total of 12,886 men and 11,715 women. In undertaking the matching of each pair of these histories, a first major issue is the 'costing' to be attached to matching operations: that is, to the substitutions, insertions or deletions of states that would be necessary in order to match - i.e. to make identical - one sequence with another. It is these 'transformation' costs that the OM algorithm is designed to minimise, and that, as minimised, will determine the degree of similarity or dissimilarity taken to exist between each pair of sequences or, in other words, that will quantify the 'distance' between them. What is therefore obviously important is that the costing adopted, and in particular the costing of substitutions, should as far as possible have a clear theoretical rationale. Insofar as such a rationale is lacking, the entire optimal matching procedure could appear disturbingly arbitrary.

As regards substitution costs, we draw on the theoretical basis of a topological model of the class mobility regime in present-day British society that has been shown to reproduce relevant empirical data to a close approximation (Bukodi, Goldthorpe and Kuha, 2016). A central feature of this model is the five hierarchical 
divisions that are recognised within the 7-class version of NS-SEC, and that are indicated by the dotted lines in Table 1. These are divisions between which mobility is systematically limited in that they relate to class positions differing in their general desirability and, further, in the advantages they offer as classes of origin and in the barriers that exist to their attainment as classes of destination. The model does, however, have two additional features. First, the hierarchical divisions between Classes 1, 2 and 3, on the one hand, and between Classes 5, 6 and 7, on the other, are taken to be in some degree offset - and limitations on mobility between them weakened - by status affinities: that is, by a 'white-collar' status affinity in the case of Classes 1, 2 and 3 and a 'blue-collar' status affinity in the case of Classes 5, 6 and 7. Second, in the case of Class 4, that of small employers and self-employed workers, a relatively high propensity for immobility is recognised, resulting from the intergenerational transmission of capital and also perhaps of family traditions, implying a further limitation on mobility between Class 4 and all other classes, independently of hierarchy effects.

The matrix of substitution costs that we apply, and that is shown in Table 3, is then directly informed by the theoretical ideas underlying the topological model. As can be seen, these costs in general increase from 1 to 5 as substitutions involve classes further apart across the five hierarchical divisions of NS-SEC; but with the modifications that, on grounds of status, a cost of 1 rather than 0 is introduced as regards substituting Class 3 for Class 5 or vice versa, and that a cost of 3 is attached 
to all substitutions involving Class 4 rather than the costs of 2, 1 or 0 that would otherwise apply. In the case of substitutions involving the two additional states of 'pre-employment' or 'class not known', little theoretical guidance can be gained and we therefore give all such substitutions half the maximum cost -2.5 . This setting aims to make these states neutral - as similar as possible to all other states.

\section{[Table 3 here]}

The further costing issue that arises is that of the costs to be attached to insertions or deletions as distinct from substitutions, the 'indel' costs. In this regard, we follow the standard practice in the literature: i.e. insofar as substitution costs have a good theoretical basis, the fixing of indel costs is essentially a matter of establishing their appropriate relation to substitution costs, given the substantive concerns of the analysis being undertaken (Aisenbrey and Fasang, 2010). Substitution operations have to do with assessing similarity; indel operations 'warp time' in order to recognise similarity that is displaced in time. With sequences of equal length consisting of relatively long spells, such as we have, indel operations will tend to have a quite limited role. We set the indel cost to its minimum - half the maximum substitution cost - so as to keep this operation in play. 


\section{The optimal matching of class histories: from the matrix of distances to typologies}

Given our research interests, it appears appropriate to undertake the $\mathrm{OM}$ for men and women separately but with the data pooled across cohorts. ${ }^{3}$ We implement the OM process by using the TraMineR package in $\mathrm{R}$ (Gabadinho et al., 2011). The outcome of the process is a matrix of minimal distances, in terms of our costing scheme, between each pair of class histories included in the analysis: to repeat, 12,886 histories for men and 11,715 for women. A vast amount of information is thus produced that is in itself impossible to digest, and we therefore follow the standard practice of complementing the matching process with a form of cluster analysis in order to move from distance matrices to typologies of class histories. We opt in this regard for Ward's minimum variance method of hierarchical clustering (Everitt et al., 2011; 76-84), which we implement through the WeightedCluster package in $\mathrm{R}$ (Studer, 2013).

Given the dendrograms we thus obtain, we find that results from a range of statistics of cluster fit (see Online Appendix 2) do not point unequivocally to a 'correct' number of clusters that should be taken as the basis of our typologies of class histories: i.e. the indication is that there is no latent class structure. This is in fact often the case with life-course data where trajectories are distributed fairly evenly i.e. without great 'lumpiness' - in, nonetheless, a highly structured space. In this 
case, while the clustering exercise has to be understood essentially as one of datareduction, it can still yield clusters that are distinct and informative (Halpin, 2014).

With a view to manageability, we have taken clusters in the range of seven to ten, and in each case constructed sequence index plots and also time-budgets showing the overall proportion of time that individuals allocated to a cluster spent in each of the states we distinguish. In the light of the results obtained, we adopt, for the purposes of our subsequent analyses, an eight-cluster typology of class histories for men and a nine-cluster typology for women. The sequence index plots for these clusters are shown in Online Appendix 3, and the relevant time-budget results are incorporated into the descriptions of the class history types that are given in Tables 4 and 5. We have then conducted tests of cluster quality using measures of 'silhouette widths' (Studer, 2013). These compare each case's distance to its cluster centre with its distance to the centre of the next nearest cluster. With men, only one cluster, that for Type 3 in Table 4, is on these measures poorly defined, while with women two clusters, for Types 4 and 9 in Table 5, are poorly defined (Online Appendix 2).

\section{[Tables 4 and 5 here]}

From Tables 4 and 5, it can be seen that the typologies for men and women are broadly similar, although three differences should be noted. First, while for men there is only one 'upward mobility' type of class history, Type 3, for women there are two, Types 3 and 4: a distinction is made between class histories where upward 
mobility occurs early - that is before age 30 - or later. Second, for men one type of class history, Type 6, is 'stability in Class 5' but no corresponding type emerges for women, who are in fact only sparsely represented in this class. And third, for women but not for men, a 'downward mobility' type, Type 7, is distinguished characterised by downward movement from Class 3 to Classes 6 and 7 .

As earlier indicated, our matching of class histories is based on pooled data for men and women in three birth cohorts. However, our first research question concerns the extent to which class histories are changing over time. What therefore we wish to know is whether across our cohorts we find systematic differences in the distributions of men and women within our typologies, and whether any such differences point to an increasing stability in class positions from labour market entry onwards and, in particular, to declining chances of upward class mobility achieved over the course of working life. The relevant distributions, with confidence intervals, are provided in Table 6.

[Table 6 here]

In the case of men, it can be seen that there is a clear increase across cohorts in the proportion of those with Type 1 class histories: that is, histories characterised by stability in Class 1, the higher level of the managerial and professional salariat, following late entry into the labour market. However, there is no similar increase in the proportion of men following Type 2 histories, characterised by late entry and 
stability in Class 2, the lower level of the salariat. Moreover, while the proportion of men with Type 3 class histories involving upward worklife mobility into Classes 1 and 2 from labour market entry in less advantaged positions does decline between the 1946 and 1958 cohorts, this decline does not continue through to the 1970 cohort. As earlier noted, Type 3 histories are less well-defined - i.e. more heterogeneous than we would wish but it could still be said that no strong evidence emerges of any sustained reduction in upward mobility chances. Finally, it may be noted that there is also no clear trend of change in Type 5 class histories that mainly involve men being mobile in their working lives from Class 5,6 or 7 positions to become selfemployed or small employers in Class 4 - a form of possible worklife advancement regarded by Bell (1972: 30) and other modernisation theorists, as being one of steadily diminishing importance (for critical comment, see Arum and Müller, 2004).

What is most notable about the results for men considered overall is in fact the rather modest degree of difference in the distributions, given the historical period spanned by the three cohorts. Already with the 1946 cohort it is class histories of a more or less stable kind that are most common, and the tendency towards greater stability in the two later cohorts is rather slight.

For women, changes in their distribution within the types of class history distinguished are more marked. As with men there is an increase - though from a very low base in the 1946 cohort - in the proportion following Type 1 histories: i.e. those characterised by late entry and stability in Class 1. At the same time, though, 
there is no increase in the proportion with Type 2 histories, involving late entry and stability in Class 2 (or, for a minority, Class 3). And, further, the two types of class history characterised by upward mobility in working life do not decrease but actually increase in numerical importance. This increase is quite pronounced with Type 3 histories of mobility mainly into Class 2 from less advantaged positions and achieved before age 30, with the proportion of women represented by this type more than doubling across the cohorts; and some increase is also suggested in the - less well-defined - Type 4 histories of mobility in later working life into Classes 2, 3 and 5 from Class 6 and 7 positions. The offsetting decline comes largely in the proportion of women following Type 9 histories: i.e. transitional movement between Classes 6 and 7.

In sum, regarding our first research question, the evidence from the changing distributions of cohort members among types of class history is somewhat equivocal. There is support for the claim that men and women who attain higher-level managerial and professional positions increasingly do so by moving into such positions at the start of their working lives. But there is no clear indication that this change is part of a general shift towards more stable class histories, and one thus entailing a declining importance of upward mobility achieved over the course of working life. 


\section{The role of education in class histories}

In regard to our second research question concerning the role of education in class histories, we undertake multinomial logistic regression analyses in which our types of class history form the dependent variable and individuals' - relative - level of educational attainment at labour market entry, together with cognitive ability, class origins and cohort, are the independent variables. Results from the Hausman and Small-Hsiao tests (available on request) indicate that in taking our types as the dependent variable no violation of the IIA (independence of irrelevant alternatives) assumption is here involved. Tables 7 and 8 show results for men and women respectively. Cohort effects are largely in line with results already reported in Table 6 and are not further discussed.

In the case of men, what can now be seen is that although high levels of educational qualification are strongly associated with Type 1, as with Type 2, histories, such histories are also associated with high levels of cognitive ability - over and above that expressed via educational attainment - and with more advantaged class origins. In other words, these histories of direct entry into, and stability within, the managerial and professional salariat cannot be taken as indicative of the operation of an education-based meritocracy in any 'pure' form. And, conversely, low cognitive ability and disadvantaged class backgrounds are revealed as being significantly associated, independently of low-level qualifications, with Type 7 and Type 8 histories characterised by life-course stability at the base of the class structure. 
Moreover, in the case of Type 3 class histories, showing upward worklife mobility, what emerges is that these are negatively linked with both the highest and the lowest levels of qualification at labour market entry, and that, while cognitive ability appears of little importance, such histories are also associated with Class 1 and Class 2 origins. What is thus indicated is a tendency for 'counter-mobility' (Girod, 1971) for men of advantaged class backgrounds whose initial educational attainment might be only modest. And from further research (Bukodi, 2016) we know that in such countermobility qualifications gained over the course of working life, are often of importance: i.e. can substitute for qualifications at labour market entry as the 'passport' to higherlevel class positions.

Finally, it may be observed that while Type 5 class histories of worklife mobility into Class 4, that of small employers and self-employed workers, show a generally negative association with qualifications (cf. Ishida, Müller and Ridge, 1995) - though also with low cognitive ability - they are at the same time strongly associated with Class 4 origins, thus again pointing to some significant amount of counter-mobility and 'class maintenance' but of a kind in which education is not involved.

\section{[Table 7 here]}

For women, broadly similar results to those for men are obtained, but the following points of difference may be noted. First, with Type 2 histories of mainly late entry into and stability within Class 2, high levels of qualification are still more important 
than with Type 1 histories of late entry into and stability within Class 1 . Women following Type 2 histories turn out to be heavily concentrated in professional occupations (school teachers, nurses and therapists predominate) that are characterised by a quite strict 'credentialism'. Second, with Type 3 histories involving mainly upward mobility into Class 2 achieved before age 30, it would appear that, in addition to advantaged class origins, cognitive ability is also of some importance, independently of education - in contrast with what is found with the broadly corresponding Type 3 for men. And third, with Type 4 histories, involving more limited upward mobility mostly after age 30, what emerges is that this type is negatively associated with educational attainment, cognitive ability and class origins alike. The most plausible hypothesis for further investigation might then be that non-cognitive attributes of some kind here play a role; and some indirect support for this possibility is found in that seven out of the ten occupations in which the women in question are most frequently found fall in the sales and personal services sectors.

[Table 8 here]

The foregoing results do then indicate that, overall, educational attainment prior to labour market entry was not 'class destiny' for our three cohorts of individuals born over the middle decades of the last century. While such attainment, or lack thereof, was often an important factor in their class histories, an education-based meritocracy would, in the light of these results, have to be regarded as, at all events, being still some way off. However, the question remains of whether, looking across the 
cohorts, we can find any evidence of change that is at least in the direction of such a meritocracy. To address this question, we have repeated the analyses of Tables 7 and 8 for each cohort separately. Space limitations prevent us from showing these further results in full (they are available on request and are in fact on essentially the same lines as those that we report). We focus therefore on the types of class history that would seem of main relevance to our theoretical concerns: that is, Types 1,3 and 5 for men, and Types 1 and 3 for women. The results for these types are presented in graphical form in Figures 1 and 2.

As can be seen, the three panels of Figure 1 provide little evidence of change across cohorts. With Type 1 histories of late entry into and stability within Class 1 , the only change that is arguably significant is that of a strengthening association with cognitive ability, independently of educational qualifications - although it is also the case that with Type 3 histories of upward worklife mobility, some tendency in the reverse direction is present. In general, what emerges could best be described as very slight, if not negligible, fluctuations around the effects that are shown in Table 7; and the persisting influence of class origins across the cohorts is of particular note.

[Figure 1 here]

Figure 2 then tells a similar story regarding the two types of women's class histories that are considered. Again, there is little indication that these histories are increasingly shaped by educational qualifications at labour market entry. With Type 
1 histories of late entry into and stability within Class 1 no directional change of any kind is apparent; and with Type 3 histories of upward mobility, the only significant change is that of a somewhat more marked association with class origins.

[Figure 2 here]

Although, then, we find across our cohorts an increase in class histories in which individuals enter, and then largely remain in, higher-level managerial and professional positions, and also that such histories are associated with high-level educational qualifications, we do not find that this association is strengthening, nor that the association with cognitive ability or with class origins is weakening. And while we further find no general decline in class histories characterised by upward worklife mobility, it again appears that entry education is not of increasing importance in such histories.

\section{Conclusions}

In this paper, we have started out from arguments, developed in their fullest form by Daniel Bell and now widely accepted, even if only implicitly, in political and public discourse, according to which in post-industrial societies educational attainment prior to labour market entry must play an increasingly dominant role in determining individuals' class positions, while factors such as cognitive ability and class origins, insofar as they are not mediated through education, will be of declining 
influence. We have sought to complement existing sociological examination of these arguments by taking Britain as an appropriate case of a post-industrial society and by exploiting the unique opportunities offered by the datasets of the British series of birth-cohort studies for a life-course or biographical approach. We have addressed two directly relevant research questions. Is it the case that individuals' class histories are becoming more stable over time - so that, in particular, the frequency of upward mobility achieved in the course of working life falls away? And, second, is it the case that any changes in the frequency of class histories of differing trajectory do reflect the growing importance of educational qualifications at labour market entry?

Our findings are mainly negative. From our optimal matching analyses of class histories and our subsequent regression analyses, we do have evidence supportive of the idea of an emergent education-based meritocracy in one respect. There is a steady increase across our cohorts of class histories of men and women that are characterised by entry into and stability within the higher levels of the managerial and professional salariat, and that are closely associated with higher-level educational qualifications. However, beyond this, our findings go largely contrary to Bell's arguments and to the conventional wisdom that had developed around them. Among men, there is no decline in the frequency of class histories involving upward worklife mobility into the higher and the lower levels of the salariat, and among women histories involving such mobility, mainly into the lower level of the salariat, become, if anything, more frequent. Moreover, in the shaping of individuals' class 
histories the part that is played by education is widely supplemented, or modified, by the independent effects of cognitive ability and class origins; and there is little indication that these factors, both of which imply deviation from the idea of an education-based meritocracy, are of declining importance.

What then, we may ask, are the flaws in supposing that an education-based meritocracy is required by the very 'logic' of a post-industrial society? We would suggest that two misjudgements are involved.

First, there is an overestimation of the importance in post-industrial economies of 'theoretical' as opposed to 'empirical' knowledge. Although knowledge and skills of a kind largely gained 'on the job' may now serve less well than previously as a basis for career advancement in the context of the - declining - manufacturing sector, as a result of scientific and technological advance, the same need not apply in the expanding - services sector (Jackson, Goldthorpe and Mills, 2005). In many occupations in this sector, and especially in sales and personal services, a high level of formal educational qualification would not appear essential for the effective performance of work tasks and roles. And opportunities are then likely to exist for individuals with only modest qualifications but with relatively high levels of basic ability, and also perhaps with relevant non-cognitive attributes, to work their way up into managerial positions - to much the same extent as could skilled manual workers in the earlier industrial economy. 
Second, there is an underestimation of the wide-ranging influence of social origins and, in particular, of the degree to which children from more advantaged origins are both motivated and able to avoid long-term downward mobility, even if, as a result of initial educational shortcomings, they do not gain immediate access to managerial or professional employment. As we have earlier noted, one important route to class maintenance for such individuals is through acquiring further qualifications over the course of working life, supported in this, perhaps, by family economic resources as, say, in the form of wealth as a 'general insurance factor' (Pfeffer and Hällsten, 2012). What is thus furthered is the tendency that we have demonstrated for upward worklife mobility often to be - as indeed it was in earlier times (Pollard, 1965) counter-mobility, serving to offset low-level labour market entry.

It is, then, in social processes of the above kind that, we would believe, the explanation chiefly lies of why, in Britain at least, education prior to labour market entry is no more class destiny today than it was half-a-century ago. 


\section{Acknowledgements}

We are grateful for funding from the Economic and Social Research Council (grant: ES/I038187/1). We would like to thank the study members from the MRC National Survey of Health and Development (NSHD) for their lifelong commitment to the study and the NSHD study team for their help and guidance in accessing the data. Data used in this publication are available to bona fide researchers upon request to the NSHD Data Sharing Committee via a standard application procedure. Further details can be found at http://www.nshd.mrc.ac.uk/data (doi: 10.5522/NSHD/Q101). 


\section{References}

Abbott, A. and Tsay, A. (2000). Sequence analysis and optimal matching methods in sociology: Review and prospect. Sociological Methods \& Research, 29, 3-33.

Aisenbrey, S. and Fasang, A. E. (2010). New life for old ideas: The "second wave" of sequence analysis bringing the "course" back into the life course. Sociological Methods $\mathcal{E}$ Research, 38, 420-62.

Arum, R and Müller, W. (2004). Self-employment dynamics in advanced economies. In Arum, R. and Müller, W. (eds.) The Reemergence of Self-Employment. Princeton: Princeton University Press, pp.1-35.

Ballarino, G. and Bernardi, F. (2016). The intergenerational transmission of inequality and education in fourteen countries: a comparison'. In Bernardi, F. and Ballarino, G. (eds.), Education, Occupation and Social Origins. Cheltenham: Edward Elgar.

Barban, N. and Billari, F. C. (2012). Classifying life course trajectories: a comparison of latent class and sequence analysis. Journal of the Royal Statistical Society, Series A, 61, 765-84.

Barone, C. and Schizzerotto, A. (2011). Career mobility, education, and intergenerational reproduction in five European societies. European Societies, 13, 331-45.

Bell, D. (1972). On meritocracy and inequality. The Public Interest, 29, 29-68.

Bell D. (1973). The Coming of Post-Industrial Society. New York: Basic Books.

Bertaux, D. (1974). Mobilité sociale biographique. Une critique de l'approche transversale. Revue française de sociologie, 15, 329-62. 
Billari, F. C. (2005). Life course analysis: two (complementary) cultures? Some reflections with examples from the analysis of the transition to adulthood. Advances in Life Course Research, 10, 261-81.

Breen, R. and Luijkx, R. (2004). Conclusions. In Breen, R. (Ed.) Social Mobility in Europe. Oxford: Oxford University Press, pp. 383-410.

Bukodi, E. (2016). Cumulative inequalities over the life-course: life-long learning and social mobility in Britain. Journal of Social Policy, forthcoming.

Bukodi, E. and Goldthorpe, J. H. (2009). Class Origins, Education and Occupational Attainment: Cross-Cohort Changes among Men in Britain. Centre for Longitudinal Studies, Working Paper 2009/3, Institute of Education, London.

Bukodi, E., Dex, S. and Goldthorpe, J.H. (2011). The conceptualisation and measurement of occupational hierarchies: A review, a proposal and some illustrative analyses. Quality $\mathcal{E}$ Quantity, 45, 623-639.

Bukodi, E. and Goldthorpe, J. H. (2016). Educational attainment - relative or absolute - as a mediator of intergenerational class mobility in Britain. Research in Social Stratification and Mobility, 43, 5-16.

Bukodi, E., Goldthorpe, J. H. and Kuha, J. (2016). The pattern of social fluidity within the British class structure: a topological model. Journal of Royal Statistical Society: Series A (Statistics in Society).

Bukodi, E., Goldthorpe, J. H., Waller, L. and Kuha, J. (2015). The mobility problem in Britain: new findings from the analysis of birth cohort data. British Journal of Sociology, 66, 93-117. 
Bühlmann, F. (2010). Routes into the British service class: feeder logics according to gender and occupational groups. Sociology, 44, 195-212.

Elliott, J. and Shepherd, P. (2006). Cohort profile: 1970 British Birth Cohort (BCS70). International Journal of Epidemiology, 35, 836-843.

Everitt, B. S., Landau, S., Leese, M. and Stahl, D. (2011). Cluster Analysis. Chichester: Wiley.

Flynn, J. R. (1987). Massive IQ gains in 14 nations. What IQ tests really measure. Psychological Bulletin, 101, 171-91.

Gabadinho, A., Ritschard, G., Müller, N. S., Studer, M. (2011). Analysing and visualizing state sequences in $\mathrm{R}$ with TraMineR. Journal of Statistical Software, 40, 1-37.

Gershuny, J. (1993). Post-industrial career structures in Britain'. In G. Esping-Andersen (ed.) Stratification and Mobility in Post-Industrial Societies. London: Sage

Girod. R. (1971). Mobilité sociale. Geneva: Droz.

Haplin, B. (2012). Multiple Imputation for Life-course Sequence Data. University of Limerick Department of Sociology Working Paper Series, WP2012-01.

Halpin, B. (2014). Three narratives of sequence analysis. In P. Blanchard, F. Bühlmann and J.A. Gauthier (eds), Advances in Sequence Analysis: Theory, Method, Applications, Springer, Berlin.

Halpin, B. and Chan, T.-W. (1998). Class careers as sequences: an optimal matching analysis of work-life histories, European Sociological Review, 14, 111-29.

HM Government (2009). New Opportunities: Fair Chances for the Future. Cm7533, London 
HM Government (2011). Opening Doors, Breaking Barriers: A Strategy for Social Mobility. London: Cabinet Office.

Ishida, H., Müller, W. and Ridge, J. (1995). Class origin, class destination, and education: A cross national study of industrial nations, American Journal of Sociology, 101, 145-93.

Jackson, M., Goldthorpe, J. H. and Mills, C. (2005) Education, employers and class mobility, Research in Social Stratification and Mobility, 23, 3-33.

Klein, D. (2014). MIMRGNS: Stata module to run margins after mi estimate. http://EconPapers.repec.org/RePEc:boc:bocode:s457795.

MacIndoe, H. and Abbott, A. (2004). Sequence analysis and optimal matching techniques for social science data. In Hardy, M. and Bryman, A. (eds.) Handbook of Data Analysis. London: Sage.

Nathan, G. (1999). A Review of Sample Attrition and Representativeness in Three Longitudinal Surveys. London: Government Statistical Service Methodological Series, 13.

OECD (2010). Economic Policy Reform: Going for Growth. OECD: Paris.

Pollard, S. (1965). The Genesis of Modern Management. Edward Arnold: London.

Pfeffer, F. T. and Hällsten, M. (2012). Mobility regimes and parental wealth: the United States, Germany and Sweden in comparison. University of Michigan, Population Studies Centre, Research Report, 12.

Power, C. and Elliott, J. (2006). Cohort profile: 1958 British Birth Cohort (National Child Development Study)', International Journal of Epidemiology, 35, 34-41. 
Rubin, D.B. (1987). Multiple Imputation for Nonresponse in Surveys. Wiley: New York.

Schoon, I. (2010). Childhood cognitive ability and adult academic attainment: Evidence from three British birth cohort studies. Longitudinal and Life-Course Studies, 1, 241-58.

Studer, M. (2013). WeightedCluster Library Manual: A Practical Guide to Creating Typologies of Trajectories in the Social Sciences with R. LIVES Working Papers, 24.

Wadsworth, M., Kuh, D., Richards, M. and Hardy, R. (2006). Cohort profile: The 1946 National Birth Cohort (MRC National Survey of Health and Development)', International Journal of Epidemiology, 35, 49-54. 
Table 1: Class (origin and destination) description

\begin{tabular}{ll}
\hline Class & \multicolumn{1}{c}{ Description } \\
\hline Class 1 & Higher managers and professionals \\
\hline Class 2 & Lower managers and professionals \\
\hline Class 3 & Intermediate occupations \\
Class 4 & Small employers and own account workers \\
Class 5 & Lower supervisory and technical occupations \\
\hline Class 6 & Semi-routine occupations \\
\hline Class 7 & Routine occupations \\
\hline
\end{tabular}


Table 2: Cases excluded from the analyses

\begin{tabular}{|c|c|c|c|c|c|c|}
\hline & \multicolumn{2}{|c|}{1946 cohort } & \multicolumn{2}{|c|}{1958 cohort } & \multicolumn{2}{|c|}{1970 cohort } \\
\hline & Men & Women & Men & Women & Men & Women \\
\hline Initial cohort $\mathrm{N}$ & 2390 & 2089 & 7237 & 7108 & 5979 & 6153 \\
\hline Excluded, \% & & & & & & \\
\hline $\begin{array}{l}\text { no known class or never having } \\
\text { significant job }\end{array}$ & 1.0 & 2.2 & 6.2 & 6.6 & 1.5 & 2.3 \\
\hline first significant job after age 30 & 0.4 & 2.6 & 3.8 & 5.8 & 0.4 & 1.0 \\
\hline $\begin{array}{l}\text { no information on class position } \\
\text { for more than } 10 \text { years }\end{array}$ & 20.6 & 15.9 & 16.7 & 22.6 & 1.9 & 8.4 \\
\hline Total excluded, \% & 21.9 & 20.7 & 26.8 & 35.0 & 3.9 & 11.7 \\
\hline Effective $\mathrm{N}$ & 1824 & 1659 & 5298 & 4622 & 5744 & 5434 \\
\hline
\end{tabular}

Note: Total effective Ns: men $=12,886$, women $=11,715$ 
Table 3: Matrix of substitution costs

\begin{tabular}{|c|c|c|c|c|c|c|c|c|c|}
\hline & Class 1 & Class 2 & Class 3 & Class 4 & Class 5 & Class 6 & Class 7 & $\begin{array}{c}\text { Not } \\
\text { known }\end{array}$ & $\begin{array}{l}\text { Pre- } \\
\text { emp. }\end{array}$ \\
\hline Class 1 & 0 & 1 & 2 & 3 & 3 & 4 & 5 & 2.5 & 2.5 \\
\hline Class 2 & & 0 & 1 & 3 & 2 & 3 & 4 & 2.5 & 2.5 \\
\hline Class 3 & & & 0 & 3 & 1 & 2 & 3 & 2.5 & 2.5 \\
\hline Class 4 & & & & 0 & 3 & 3 & 3 & 2.5 & 2.5 \\
\hline Class 5 & & & & & 0 & 1 & 2 & 2.5 & 2.5 \\
\hline Class 6 & & & & & & 0 & 1 & 2.5 & 2.5 \\
\hline Class 7 & & & & & & & 0 & 2.5 & 2.5 \\
\hline Not known & & & & & & & & 0 & 2.5 \\
\hline Pre-empl. & & & & & & & & & 0 \\
\hline
\end{tabular}


Table 4: Class history typology, men

Types

Dominant class positions ${ }^{1}$

1) Majority: Late entry and stability in Class 1

Minority: Upward mobility to Class 1 from Classes 2 and 3, mainly before age 30

2) Majority: Late entry and stability in Class 2

Minority: Upward mobility to Class 2 from Class 3, mainly before age 30

3) Majority: Upward mobility to Classes 1, 2 and 3 from Classes 4, 5, 6, 7, mainly after age 30 Minority: Downward mobility to Classes 4, 5, 6, 7 from Classes 1, 2, 3, mainly after age 30

4) Majority: Stability in Class 3

Minority: Upward mobility to Classes 1 and 2 from Class 3, mainly after age 30

5) Majority: Mobility to Class 4 from Classes 5, 6, 7, mainly before age 30 Minority: Stability in Class 4

6) Majority: Stability in Class 5

Minority: Upward mobility to Class 5, mainly before age 30

7) Majority: Stability in Class 6

Minority: Mobility to Class 6 from Classes 5 and 7, mainly before age 30

Class 6: 66\%; Class 7: 9\%;

Pre-employment: $12 \%$

8) Majority: Mobility into and out of Class 7, mainly after age 30

Class 7: 65\%; Class 6: 16\% Minority: Stability in Class 7

Note 1: \% of time spent in the given class positions between ages 16 and 38 . 
1) Majority: Late entry and stability in Class 1

Minority: Upward mobility to Class 1 from Classes 2 and 3, mainly before age 30

2) Majority: Late entry and stability in Class 2

Minority: Late entry and stability in Class 3

3) Majority: Upward mobility to Class 2 from Classes 3 and 6, mainly before age 30

Minority: Stability in Class 2

4) Majority: Upward mobility to Classes 2, 3 and 5 from Classes 6 and 7, mainly after age 30 Minority: Mobility between Classes 4, 5, 6 and 7

5) Majority: Stability in Class 3

Minority: Mobility to Class 3 from Class 6, mainly before age 30

6) Majority: Mobility to Class 4 from Classes 3, 6, 7, mainly before age 30 Minority: Stability in Class 4

7) Majority: Downward mobility to Classes 6 and 7 from Class 3

8) Majority: Stability in Class 6

Minority: Upward mobility to Class 6 from Class 7, mainly before age 30

9) Majority: Mobility between Class 6 and 7

Minority: Stability in Class 7
Class 1: 59\%; Pre-employment: 22\%

Class 2: 46\%; Class 3: 9\%;

Pre-employment: 33\%

Class 2: 56\%; Class 3: 21\%

Class 6: 36\%; Class 7: 18\%; Class 5: 13\%

Class 2 and Class 3: $12 \%$

Class 3: $79 \%$

Class 4: 45\%; Class 3: 16\%; Class 6: $11 \%$

Class 7: $10 \%$

Class 3: 43\%; Class 6: 27\%; Class 7: 12\%

Class 6: 81\%; Class 7: 13\%

Class 7: 54\%; Class 6: 23\%

Pre-employment: $10 \%$

Note 1: \% of time spent in the given class positions between ages 16 and 38. 
Table 6: Distribution of class history types across cohorts, \% with 95\% confidence intervals in brackets

\begin{tabular}{|c|c|c|c|c|c|c|}
\hline & \multicolumn{2}{|c|}{1946 cohort } & \multicolumn{2}{|c|}{1958 cohort } & \multicolumn{2}{|c|}{1970 cohort } \\
\hline \multicolumn{7}{|c|}{ Men } \\
\hline \multirow[t]{2}{*}{ Type 1} & \multicolumn{2}{|c|}{10.7} & \multicolumn{2}{|c|}{15.4} & \multicolumn{2}{|c|}{18.8} \\
\hline & {$[9.1$} & 12.3] & {$[14.4$} & 16.3] & {$[17.8$} & 19.8] \\
\hline \multirow[t]{2}{*}{ Type 2} & \multicolumn{2}{|c|}{14.0} & \multicolumn{2}{|c|}{13.2} & \multicolumn{2}{|c|}{13.7} \\
\hline & {$[12.3$} & $15.8]$ & {$[12.3$} & 14.1] & {$[12.8$} & 14.6] \\
\hline \multirow[t]{2}{*}{ Type 3} & \multicolumn{2}{|c|}{14.8} & \multicolumn{2}{|c|}{11.8} & \multicolumn{2}{|c|}{11.7} \\
\hline & [12.8 & $16.8]$ & {$[10.9$} & 12.7] & {$[10.8$} & 12.5] \\
\hline \multirow[t]{2}{*}{ Type 4} & \multicolumn{2}{|c|}{9.0} & \multicolumn{2}{|c|}{9.0} & \multicolumn{2}{|c|}{8.4} \\
\hline & {$[7.4$} & 10.5] & {$[8.2$} & 9.8] & {$[7.6$} & 9.1] \\
\hline \multirow[t]{2}{*}{ Type 5} & \multicolumn{2}{|c|}{9.1} & \multicolumn{2}{|c|}{12.3} & \multicolumn{2}{|c|}{11.3} \\
\hline & {$[7.4$} & 10.7] & {$[11.4$} & 13.2] & [10.5 & 12.2] \\
\hline \multirow[t]{2}{*}{ Type 6} & \multicolumn{2}{|c|}{12.9} & \multicolumn{2}{|c|}{9.3} & & \\
\hline & {$[11.0$} & $14.8]$ & {$[8.5$} & 10.1] & {$[8.4$} & 9.9] \\
\hline Type 7 & & & & & & \\
\hline & {$[6.9$} & 10.1] & {$[10.6$} & 12.4] & {$[9.9$} & 11.6] \\
\hline Type 8 & & & & & & \\
\hline & [18.7] & 23.3] & {$[16.4$} & 18.4] & {$[15.2$} & 17.2] \\
\hline & & & Wome & & & \\
\hline Type 1 & & & & & & \\
\hline & {$[0.3$} & $1.1]$ & {$[4.1$} & 5.3] & {$[6.0$} & 7.4] \\
\hline Type 2 & & & & & & \\
\hline & {$[9.5$} & 12.6] & {$[10.6$} & 12.5] & {$[10.3$} & 11.9] \\
\hline Type 3 & & & & & & \\
\hline & {$[6.0$} & 9.0] & {$[12.3$} & 14.3] & {$[16.6$} & 18.7] \\
\hline Type 4 & & & & & & \\
\hline & {$[5.1$} & $8.1]$ & {$[6.2$} & 7.7] & {$[7.3$} & 8.7] \\
\hline Type 5 & & & & & & \\
\hline & {$[26.0$} & 31.1] & {$[21.1$} & 23.5] & {$[21.0$} & 23.2] \\
\hline Type 6 & & & & & & \\
\hline & {$[4.5$} & 7.1] & {$[8.3$} & 9.9] & {$[5.8$} & 7.1] \\
\hline Type 7 & & & & & & \\
\hline & {$[7.7$} & 11.1] & {$[10.7$} & 12.6] & {$[7.0$} & 8.4] \\
\hline Type 8 & & & & & & \\
\hline & {$[8.9$} & 12.5] & {$[5.6$} & 7.0] & {$[9.5$} & 11.1] \\
\hline Type 9 & & & & & & \\
\hline & {$[17.4$} & 22.0] & {$[13.1$} & 15.1] & {$[9.1$} & 10.7] \\
\hline
\end{tabular}

Note: Sequence types are characterised in Table 4 and 5 . 
Table 7: Effects of relative level of educational qualifications at labour market entry, cognitive ability in childhood and class of origin on the probability of being found in different class history types, men (average marginal effects, \%)

\begin{tabular}{|c|c|c|c|c|c|c|c|c|c|c|c|c|c|c|c|c|}
\hline \multirow{2}{*}{ Entry education } & \multicolumn{2}{|c|}{ Type 1} & \multicolumn{2}{|l|}{ Type 2} & \multicolumn{2}{|c|}{ Type 3} & \multicolumn{2}{|c|}{ Type 4} & \multicolumn{2}{|c|}{ Type 5} & \multicolumn{2}{|c|}{ Type 6} & \multicolumn{2}{|c|}{ Type 7} & \multicolumn{2}{|l|}{ Type 8} \\
\hline & & & & & & & & & & & & & & & & \\
\hline Top level & 21.1 & $* *$ & 11.6 & ** & -7.3 & $* *$ & -6.6 & $* *$ & -2.9 & $* *$ & -6.3 & $* *$ & -3.4 & ** & -6.2 & ** \\
\hline 3rd level (ref.) & 0.0 & & 0.0 & & 0.0 & & 0.0 & & 0.0 & & 0.0 & & 0.0 & & 0.0 & \\
\hline 2nd level & -8.8 & $* *$ & -5.6 & ** & -1.8 & & -4.0 & $* *$ & 4.4 & $* *$ & 2.9 & * & 4.0 & ** & 8.8 & ** \\
\hline Bottom level & -4.8 & $* *$ & -6.8 & ** & -5.6 & $* *$ & -8.6 & $* *$ & 3.6 & $* *$ & -0.4 & & 7.0 & ** & 15.5 & $* *$ \\
\hline \multicolumn{17}{|l|}{ Cognitive ability } \\
\hline Top 2 quintiles & 4.9 & $* *$ & 3.7 & ** & 1.5 & & 0.7 & & 1.7 & & -3.5 & $* *$ & -2.7 & ** & -2.3 & \\
\hline Middle (ref.) & 0.0 & & 0.0 & & 0.0 & & 0.0 & & 0.0 & & 0.0 & & 0.0 & & 0.0 & \\
\hline Bottom 2 quintiles & -3.0 & $* *$ & -3.4 & ** & -1.1 & & -2.8 & $* *$ & -2.2 & * & -0.6 & & 3.2 & ** & 5.8 & ** \\
\hline \multicolumn{17}{|l|}{ Class of origin } \\
\hline Classes $1 \& 2$ & 6.9 & $* *$ & 5.6 & ** & 2.8 & $* *$ & 2.5 & $* *$ & 1.4 & & -2.1 & * & -5.2 & ** & -12.0 & $* *$ \\
\hline Classes $3 \& 5$ & 4.4 & $* *$ & 1.9 & $*$ & 0.1 & & 1.6 & & 1.3 & & 0.6 & & -2.0 & $*$ & -7.9 & ** \\
\hline Class 4 & 0.2 & & 0.9 & & -0.1 & & -1.8 & & 13.5 & $* *$ & -3.0 & $* *$ & -2.4 & $*$ & -7.2 & $* *$ \\
\hline Classes 6\&7 (ref.) & 0.0 & & 0.0 & & 0.0 & & 0.0 & & 0.0 & & 0.0 & & 0.0 & & 0.0 & \\
\hline \multicolumn{17}{|l|}{ Cohort } \\
\hline 1946 & -5.5 & $* *$ & 0.3 & & 3.9 & $* *$ & 0.8 & & -3.2 & $* *$ & 4.3 & $* *$ & -3.1 & ** & 2.6 & $*$ \\
\hline 1958 (ref.) & 0.0 & & 0.0 & & 0.0 & & 0.0 & & 0.0 & & 0.0 & & 0.0 & & 0.0 & \\
\hline 1970 & 2.7 & $* *$ & -0.1 & & -0.3 & & -0.4 & & -1.8 & $* *$ & 0.5 & & -0.2 & & -0.4 & \\
\hline
\end{tabular}

**: $\mathrm{p}<0.01 ; *$ : $\mathrm{p}<0.05$

Note: Sequence types are characterised in Table 4 and 5. 
Table 8: Effects of relative level of educational qualifications at labour market entry, cognitive ability in childhood and class of origin on the probability of being found in different class history types, women (average marginal effects, \%)

\begin{tabular}{|c|c|c|c|c|c|c|c|c|c|c|c|c|c|c|c|c|c|c|}
\hline Entry education & \multicolumn{2}{|c|}{ Type 1} & \multicolumn{2}{|c|}{ Type 2} & \multicolumn{2}{|c|}{ Type 3} & \multicolumn{2}{|c|}{ Type 4} & \multicolumn{2}{|c|}{ Type 5} & \multicolumn{2}{|c|}{ Type 6} & \multicolumn{2}{|c|}{ Type 7} & \multicolumn{2}{|c|}{ Type 8} & \multicolumn{2}{|c|}{ Type 9} \\
\hline Top level & 6.9 & $* *$ & 34.5 & ** & -8.9 & $* *$ & -3.8 & $* *$ & -15.5 & $* *$ & -1.4 & & -6.8 & $* *$ & -2.9 & $* *$ & -2.1 & $*$ \\
\hline 3rd level (ref.) & 0.0 & & 0.0 & & 0.0 & & 0.0 & & 0.0 & & 0.0 & & 0.0 & & 0.0 & & 0.0 & \\
\hline 2nd level & -1.8 & $* *$ & -3.7 & $* *$ & -10.4 & $* *$ & 2.4 & $* *$ & 1.0 & & 0.1 & & 3.5 & $* *$ & 4.2 & $* *$ & 4.8 & ** \\
\hline Bottom level & -0.5 & & 0.6 & & -13.6 & ** & 4.6 & $* *$ & -17.2 & $* *$ & 0.4 & & -3.6 & ** & 9.9 & ** & 19.6 & ** \\
\hline \multicolumn{19}{|l|}{ Cognitive ability } \\
\hline Top 2 quintiles & 2.6 & $* *$ & 1.3 & & 2.9 & * & -0.9 & & 2.1 & & -1.6 & & -0.6 & & -2.5 & $* *$ & -3.4 & $*$ \\
\hline Middle (ref.) & 0.0 & & 0.0 & & 0.0 & & 0.0 & & 0.0 & & 0.0 & & 0.0 & & 0.0 & & 0.0 & \\
\hline Bottom 2 quintiles & -1.0 & & -1.4 & & -1.9 & & 1.8 & * & -4.5 & $* *$ & -0.6 & & -0.7 & & 3.0 & $* *$ & 5.4 & ** \\
\hline \multicolumn{19}{|l|}{ Class of origin } \\
\hline Classes $1 \& 2$ & 2.0 & $* *$ & 3.2 & $* *$ & 3.3 & ** & -1.6 & * & 0.1 & & 2.3 & ** & -1.4 & & -3.4 & $* *$ & -4.5 & ** \\
\hline Classes $3 \& 5$ & -0.2 & & 0.7 & & 2.4 & $*$ & -1.1 & & 2.5 & * & 0.6 & & 0.7 & & -2.7 & $* *$ & -3.0 & ** \\
\hline Class 4 & -1.2 & $*$ & 0.5 & & 1.8 & & -0.9 & & -1.6 & & 4.2 & $* *$ & 0.0 & & -1.1 & & -2.0 & \\
\hline Classes 6\&7 (ref.) & 0.0 & & 0.0 & & 0.0 & & 0.0 & & 0.0 & & 0.0 & & 0.0 & & 0.0 & & 0.0 & \\
\hline \multicolumn{19}{|l|}{ Cohort } \\
\hline 1946 & -3.0 & $* *$ & 6.5 & $* *$ & -4.3 & $* *$ & -1.8 & * & 7.8 & $* *$ & -3.5 & $* *$ & -2.5 & $* *$ & 1.4 & & -0.7 & \\
\hline 1958 (ref.) & 0.0 & & 0.0 & & 0.0 & & 0.0 & & 0.0 & & 0.0 & & 0.0 & & 0.0 & & 0.0 & \\
\hline 1970 & 1.8 & $* *$ & -0.4 & & 3.7 & $* *$ & 1.2 & * & 0.6 & & -3.2 & $* *$ & -3.6 & $* *$ & 4.5 & $* *$ & -4.7 & ** \\
\hline
\end{tabular}

**: $\mathrm{p}<0.01 ; *: \mathrm{p}<0.05$

Note: Sequence types are characterised in Table 4 and 5 . 
Figure 1: Effects of relative level of educational qualifications at labour market entry, cognitive ability in childhood and class of origin on the probability of being found in three class history types by cohort, men (average marginal effects, \%)
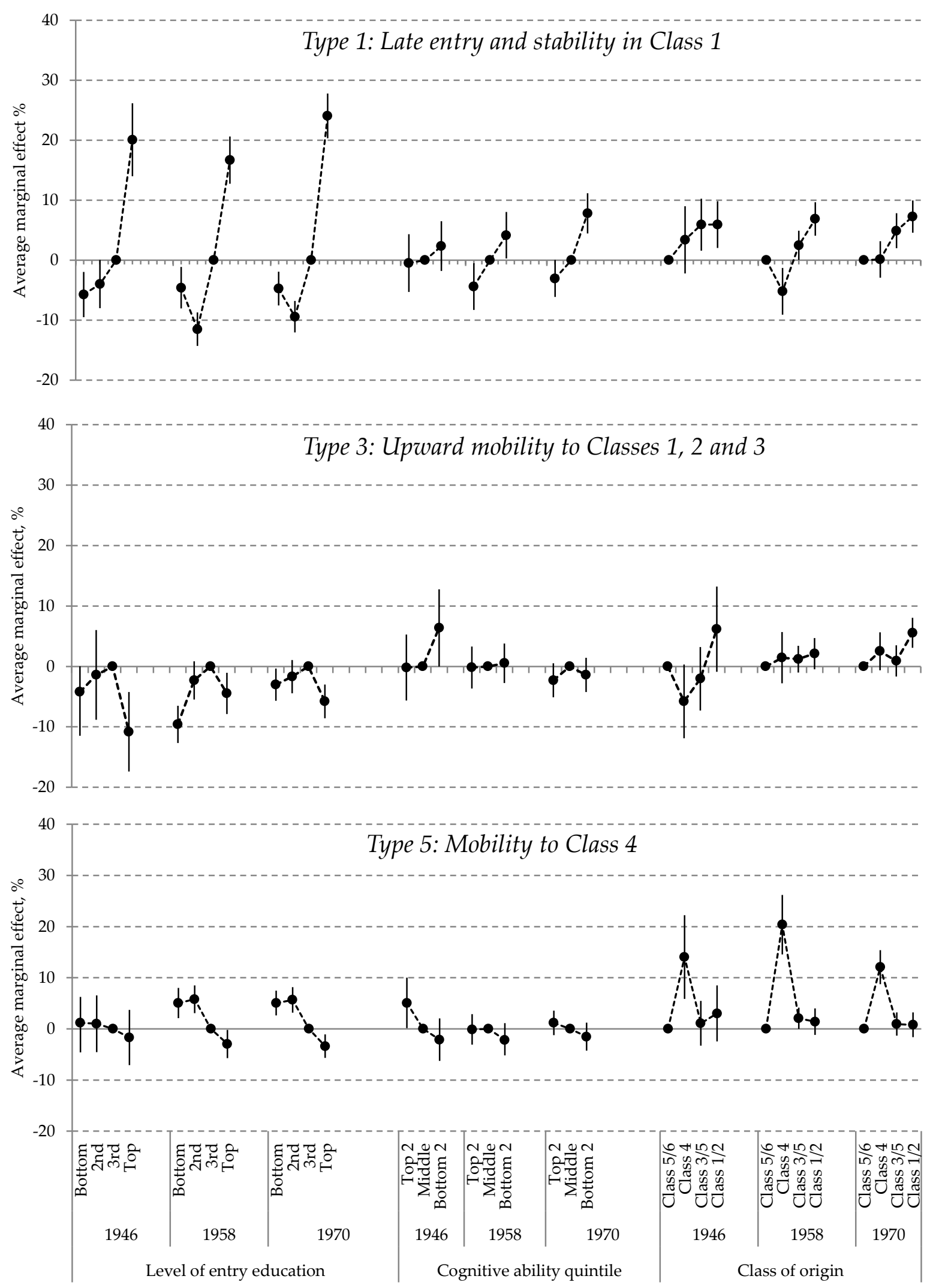
Figure 2: Effects of relative level of educational qualification at labour market entry, cognitive ability in childhood and class of origin on the probability of being found in three class history types by cohort, women (average marginal effects, \%)

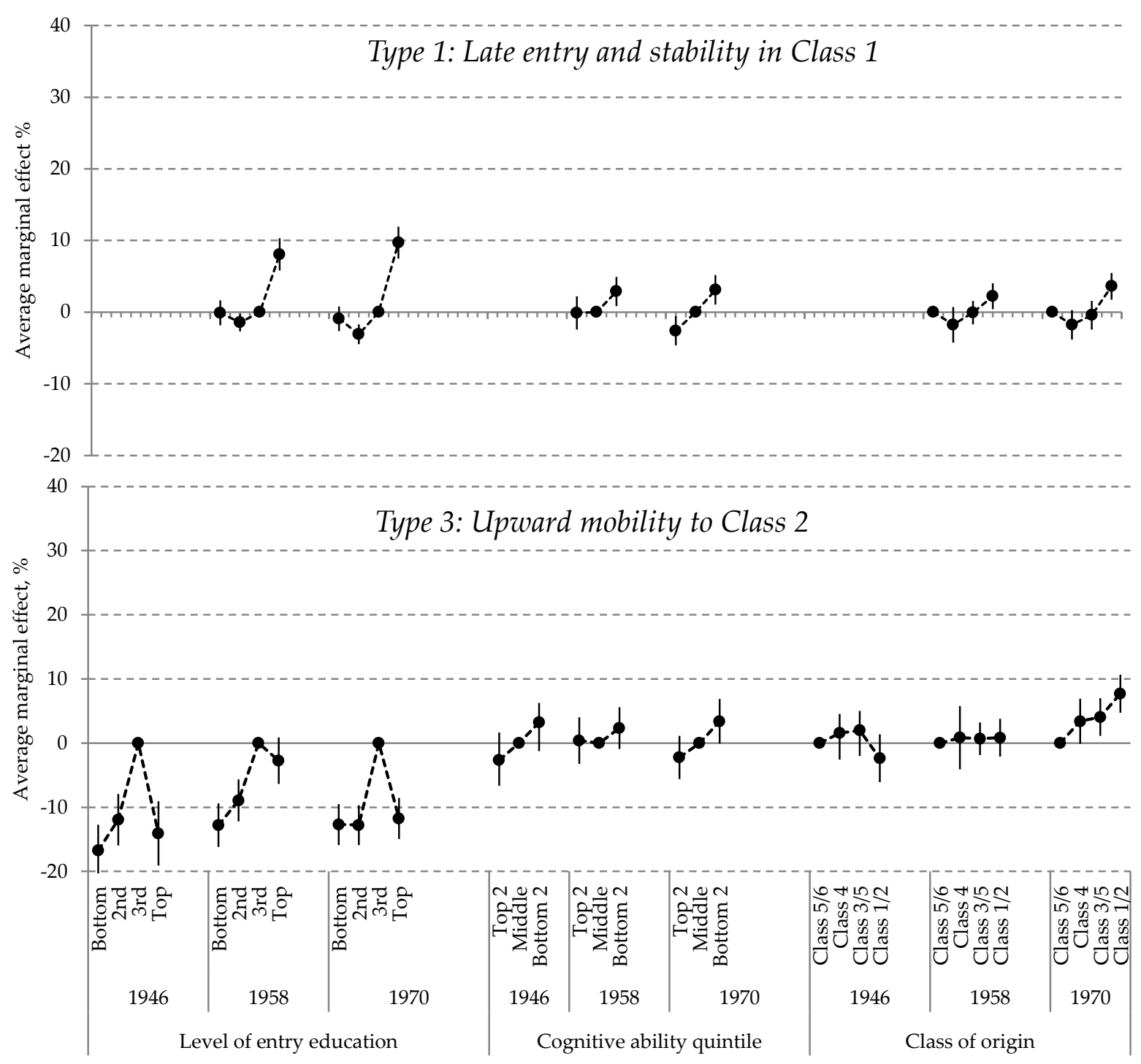




\section{Online Appendix 1: Constructing the variable of relative level of}

\section{educational qualification at labour market entry}

For the general purposes of our research based on the British birth cohort studies we have created an ordered eight-category classification of educational qualifications, both academic and vocational, that ranges from 'no qualifications' to 'postgraduate qualifications'. This is shown in Table 1.

Table 1: The eight-category educational qualification classification

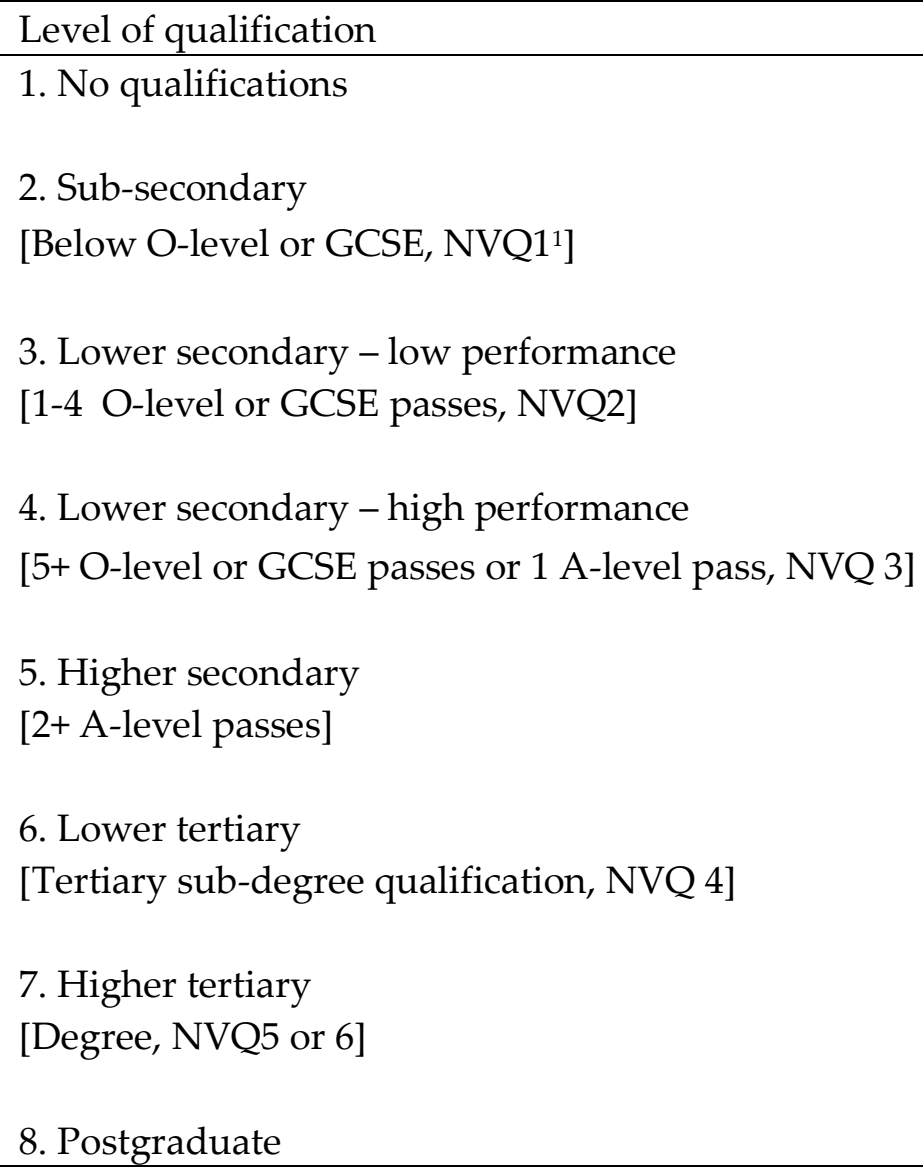

Note: ${ }^{1}$ : NVQ refers to the British National Vocational Qualifications classification which distinguishes the 6 levels indicated. 
However, for reasons indicated in the text, we believe that, where education is being taken as an independent variable in regard to some aspect of labour market performance, it is more appropriate that it should be treated in relative rather than in absolute terms. In Authors (2016) we have proposed and implemented a relativised version of the classification of Table 1 in which the eight categories are allocated to one or other of four different levels according to the numbers in each cohort holding them, and with the aim of approximating as closely to 'educational quartiles' as the lumpiness of the original distributions permits. This allocation is shown in Table 2.

Table 2: The allocation of the 8 categories of educational qualification to four relative levels

\begin{tabular}{llll}
\hline & \multicolumn{1}{c}{1946} & & \multicolumn{1}{c}{1958} \\
\hline Level 1 (bottom) & 1 & 1,2 & 1,2, \\
2nd level & 2,3 & 3 & 3, \\
3rd level & 4 & 4,5 & $4,5,6$ \\
Level 4 (top) & $5,6,7,8$ & $6,7,8$ & 7,8 \\
\hline
\end{tabular}

In the paper referred to, our concern is with the highest level of educational qualification that cohort members had attained - that is, by age 38. But in the present paper we are concerned specifically with level of qualification at labour market entry. It is therefore desirable to relativise the classification further according to age at entry. To this end, we distinguish five age-groups - 16-18, 19-21, 22-24, 25-27 and 28-30 - and, for the 1958 and 1970 cohorts, allocate cohort members to the four relative educational levels as is shown in Table 3. We do this allocation in two steps. First, based on the distribution of cohort members' highest level of qualification in each of the five age-groups, we generate five four-level variables of relative 
education, i.e. approximations to educational quartiles. Second, we combine these five variables, depending on the cohort member's age at labour market entry. For example, if a member of the 1958 cohort entered the labour market at age 22, with a category 4 qualification on the 8-level scale of Table 1, he or she would be placed see Table 3 - at the third relative level; but if a member of the 1970 cohort entered the labour market at age 22, also with a category 4 qualification, he or she would be placed only at the second relative level. As noted in the text, we are unable to do likewise with members of the 1946 cohort since we have information only on their qualifications at age 26. For this cohort, therefore, the allocation of Table 2 is retained.

Table 3: The allocation of the 8 categories of educational qualification to four relative levels by age at labour market entry, 1958 and 1970 cohorts

\begin{tabular}{|c|c|c|c|c|c|c|c|c|c|c|}
\hline & \multicolumn{5}{|c|}{$\begin{array}{c}1958 \text { cohort } \\
\text { Age at labour market entry }\end{array}$} & \multicolumn{5}{|c|}{$\begin{array}{c}1970 \text { cohort } \\
\text { Age at labour market entry }\end{array}$} \\
\hline & $16-18$ & $19-21$ & $22-24$ & $25-27$ & $28-30$ & $16-18$ & $19-21$ & $22-24$ & $25-27$ & $28-30$ \\
\hline Bottom level & 1 & 1,2 & 1,2 & 1,2 & 1,2 & 1 & 1,2 & 1,2 & $1,2,3$ & $1,2,3$ \\
\hline 2nd level & 2,3 & 3 & 3 & 3 & 3 & 2,3 & 3 & 3,4 & 4 & 4 \\
\hline 3rd level & 4 & 4 & 4,5 & 4,5 & $4,5,6$ & 4 & 4 & 5,6 & 5,6 & 5,6 \\
\hline Top level & 5,6 & $5,6,7$ & $6,7,8$ & $6,7,8$ & 7,8 & 5,6 & $5,6,7$ & 7,8 & 7,8 & 7,8 \\
\hline
\end{tabular}

The distributions of men and women in our three cohorts by the variable of relative level of educational qualification at labour market entry, constructed as above, are shown in Table 4. As can be seen from the table, the proportions of cohort members at each relative level range from 15 to 36 per cent, although in sixteen cases out of the 
twenty-four the proportions fall between 20 and 30 per cent. Statistical techniques could be applied to bring the proportions closer to quartiles but only at cost of no longer having each level made up of the specific qualifications referred to in Table 1. It is, however, these qualifications that are known to the various parties in labour markets and that can be taken to influence the decisions they make.

Table 4: Distribution of cohort members by relative level educational qualification at labour market entry $(\%)$

\begin{tabular}{|c|c|c|c|c|c|c|}
\hline & \multicolumn{2}{|c|}{1946 cohort } & \multicolumn{2}{|c|}{1958 cohort } & \multicolumn{2}{|c|}{1970 cohort } \\
\hline & Men & Women & Men & Women & Men & Women \\
\hline Bottom level & 32.2 & 35.6 & 27.2 & 21.1 & 28.7 & 23.2 \\
\hline 2nd level & 25.6 & 34.5 & 32.5 & 34.0 & 27.6 & 29.2 \\
\hline 3rd level & 18.0 & 14.8 & 20.0 & 21.2 & 20.5 & 24.0 \\
\hline Top level & 24.2 & 15.1 & 20.3 & 23.7 & 23.2 & 23.6 \\
\hline Total & 100.0 & 100.0 & 100.0 & 100.0 & 100.0 & 100.0 \\
\hline
\end{tabular}




\section{Online Appendix 2: Statistics of cluster fit}

Figures 1.1 and 1.2 plot the Calinski - Harabasz index $(\mathrm{CH})$, the squared version of $\mathrm{CH}(\mathrm{CHsq})$ and the average silhouette width for weighted data (ASWw) for different cluster solutions.

Figure 1.1: Statistics of cluster fit by number of clusters, men

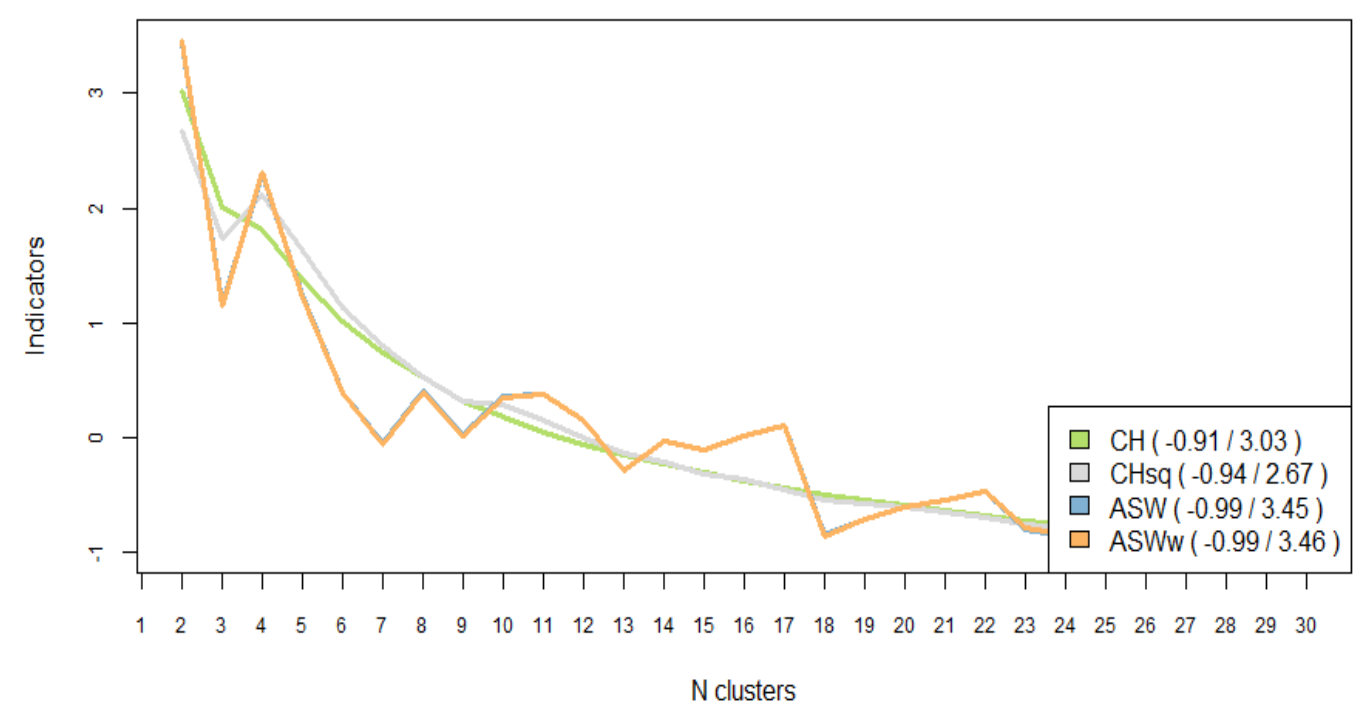

Figure 1.2: Statistics of cluster fit by number of clusters, women

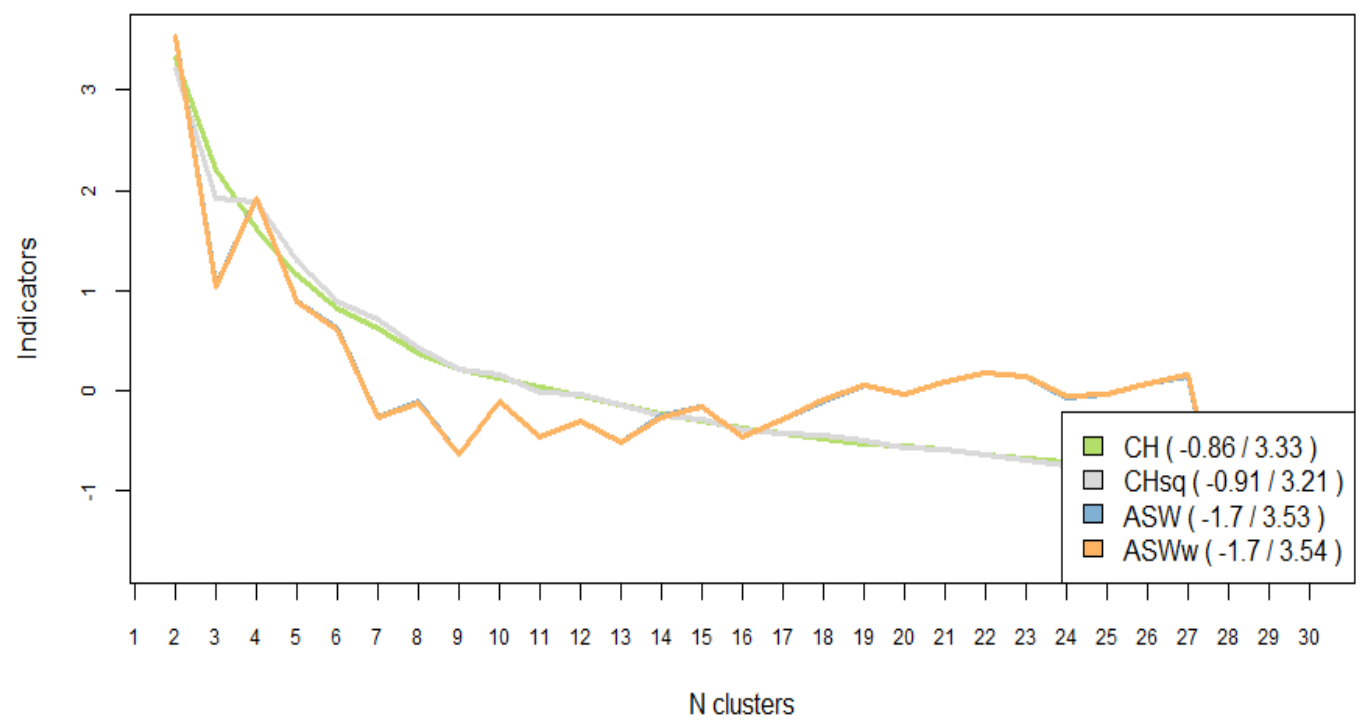


Figures 2.1 and 2.2 plot the measures of 'silhouette width' for our preferred cluster solutions - an eight-cluster typology of class histories for men and a nine-cluster typology for women.

Figure 2.1: Cluster 'silhouette width' for the eight-cluster typology of class histories for men

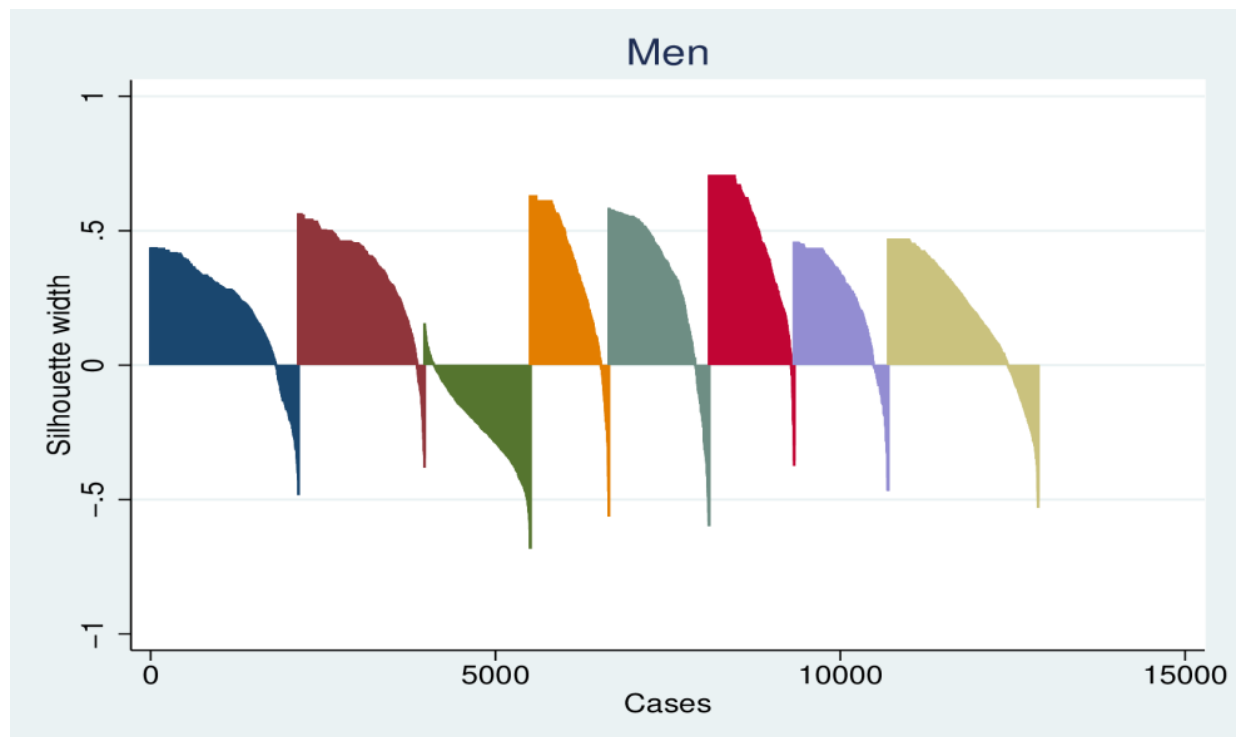

Figure 2.2: Cluster 'silhouette width' for the nine-cluster typology of class histories for women

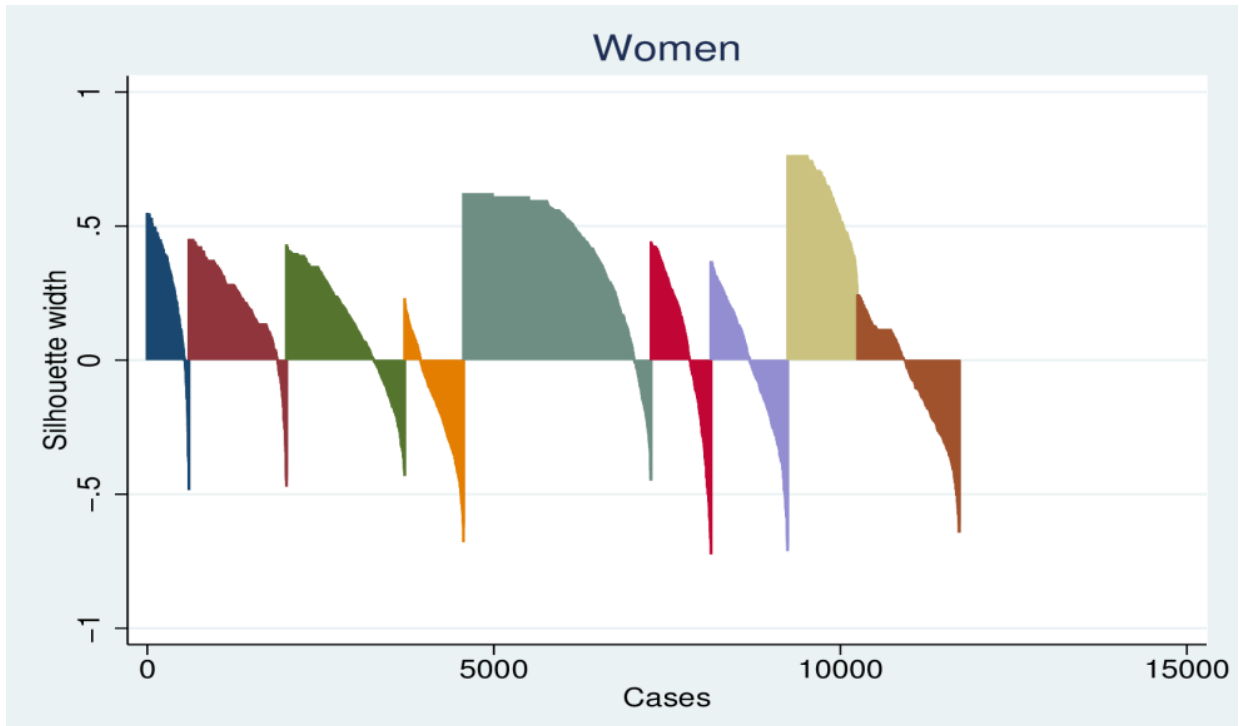




\section{Online Appendix 3: Sequence index plots}

Figure 1: Sequence index plots, men

Type 1

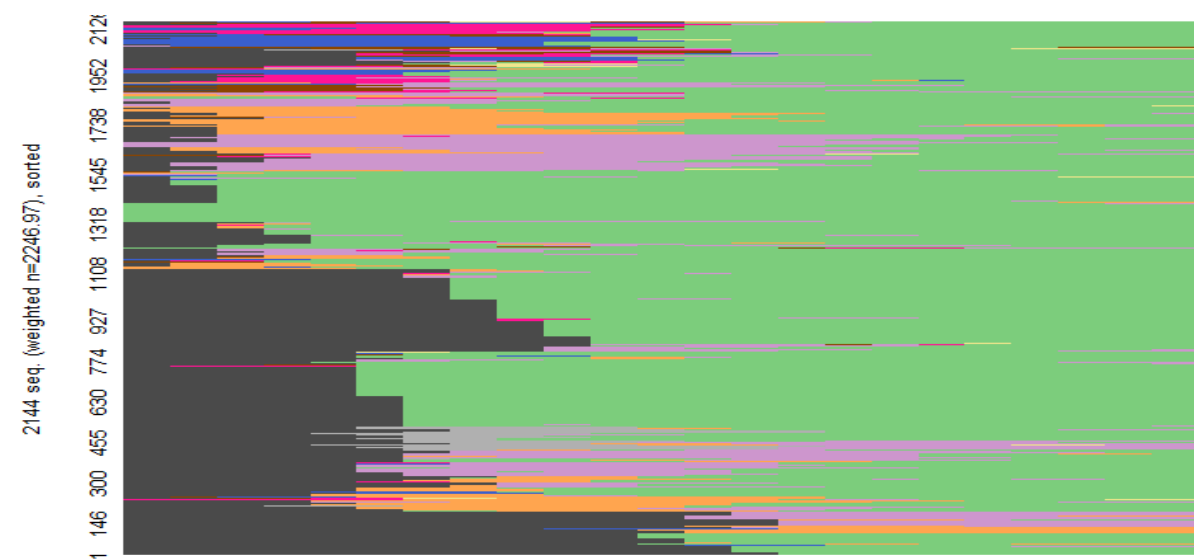

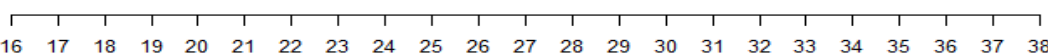

Type 3

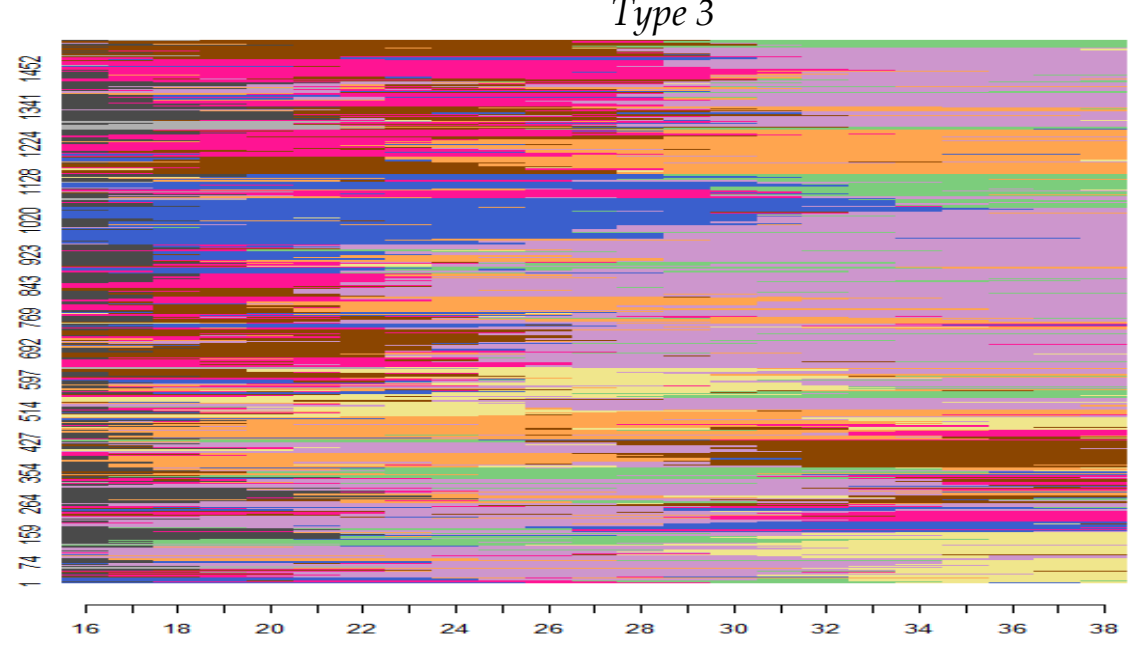

Type 2

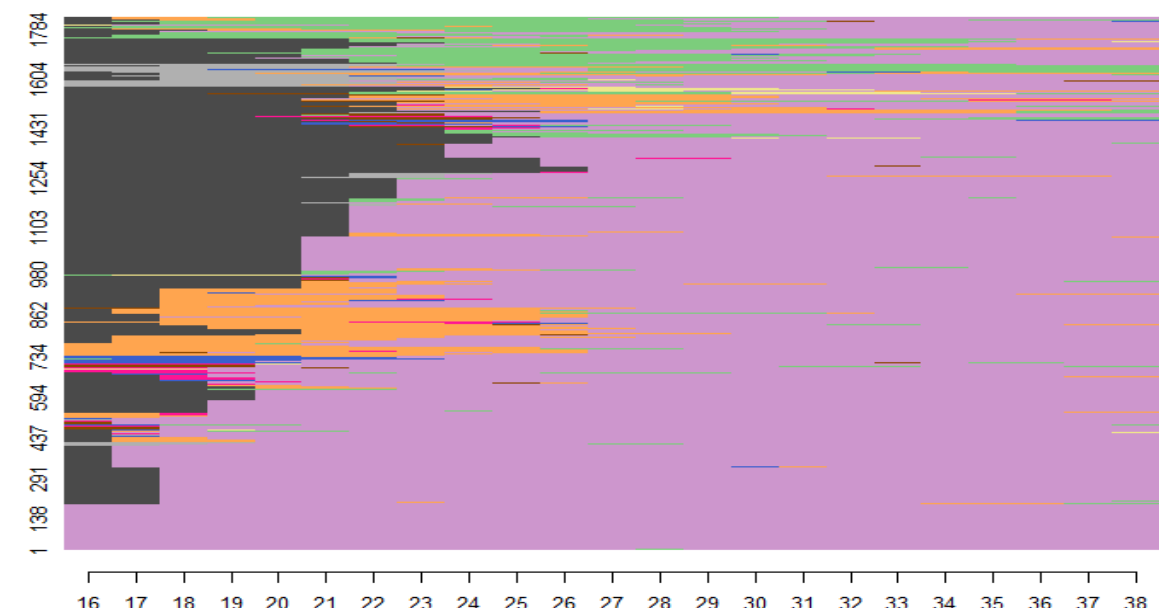

Type 4

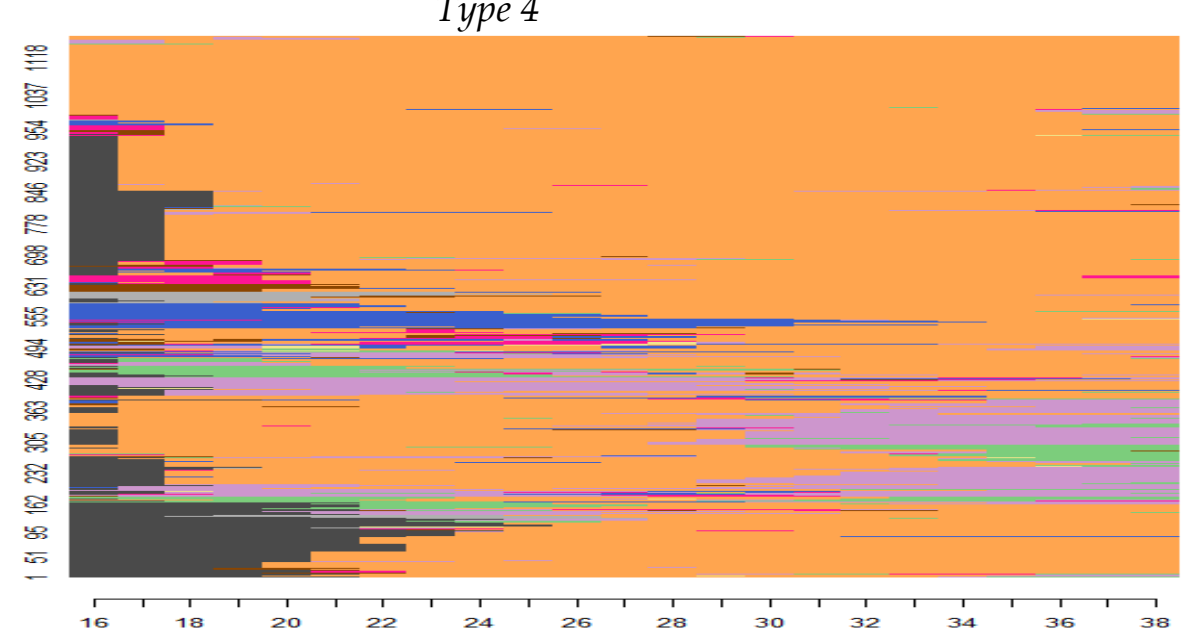


Figure 1: Sequence index plots, men (cont.)

Type 5

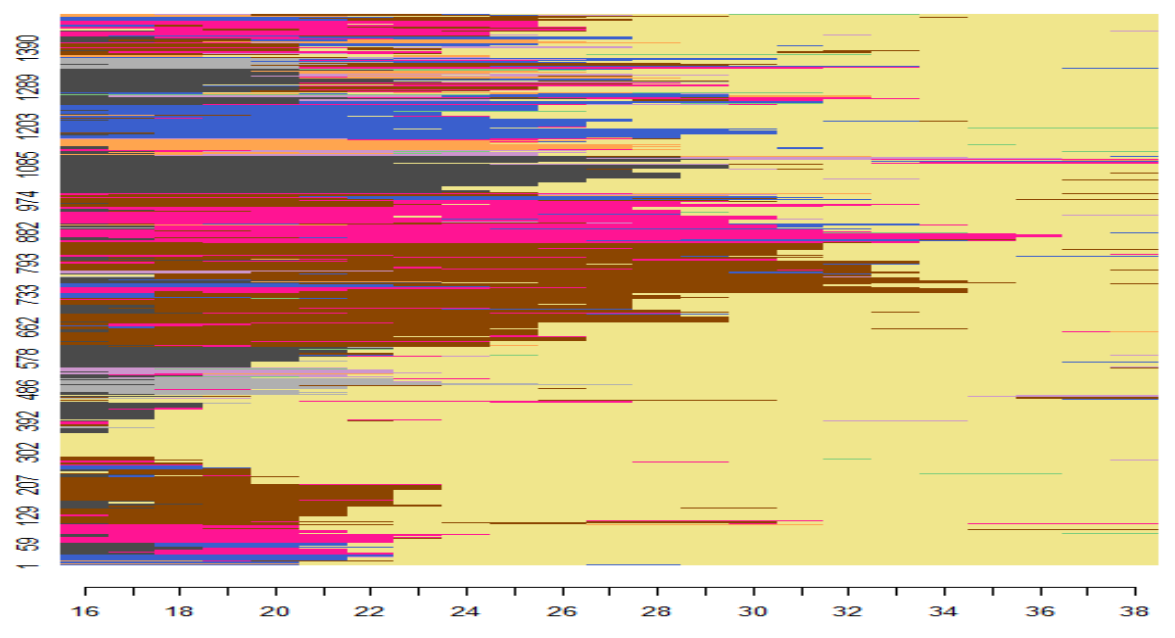

Type 7

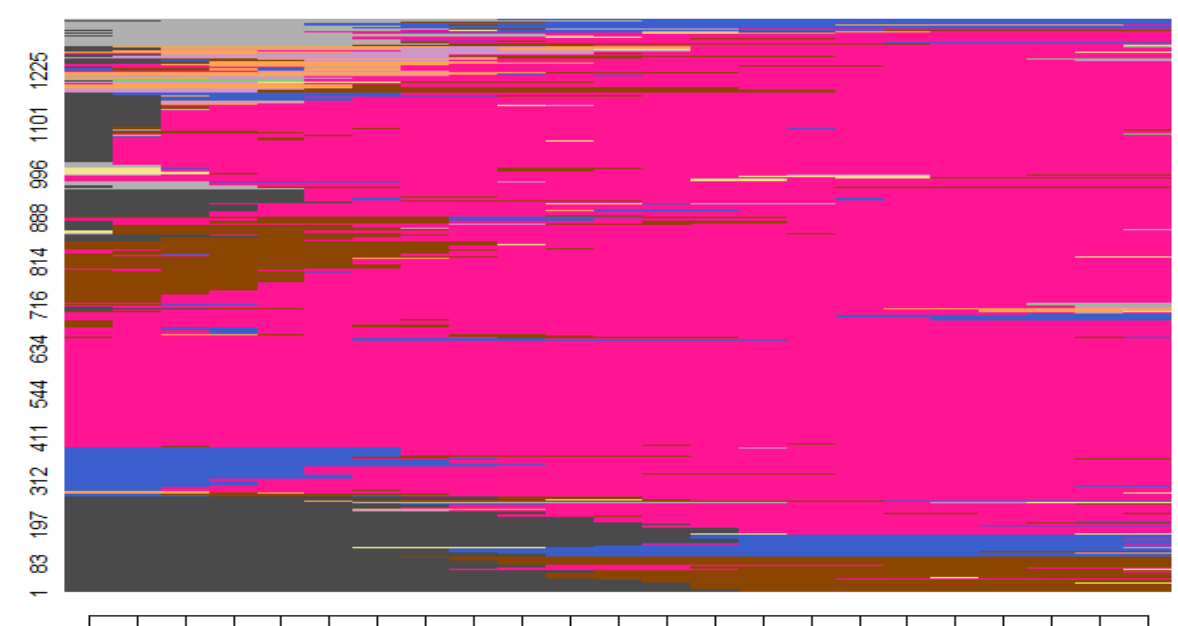

\begin{tabular}{lllllllllllllllllllllllll}
\hline 16 & 1 & 18 & 1 & 1 & 1 & 1 & 1 & 1 & 1 & 1 & 1 & 1 & 1 & 1 & 1 & 1 & 1 & 1 & 1 & 1 & 1 \\
16 & 18 & 20 & 21 & 22 & 23 & 24 & 25 & 26 & 27 & 28 & 29 & 30 & 31 & 32 & 33 & 34 & 35 & 36 & 37 & 38
\end{tabular}
Type 6

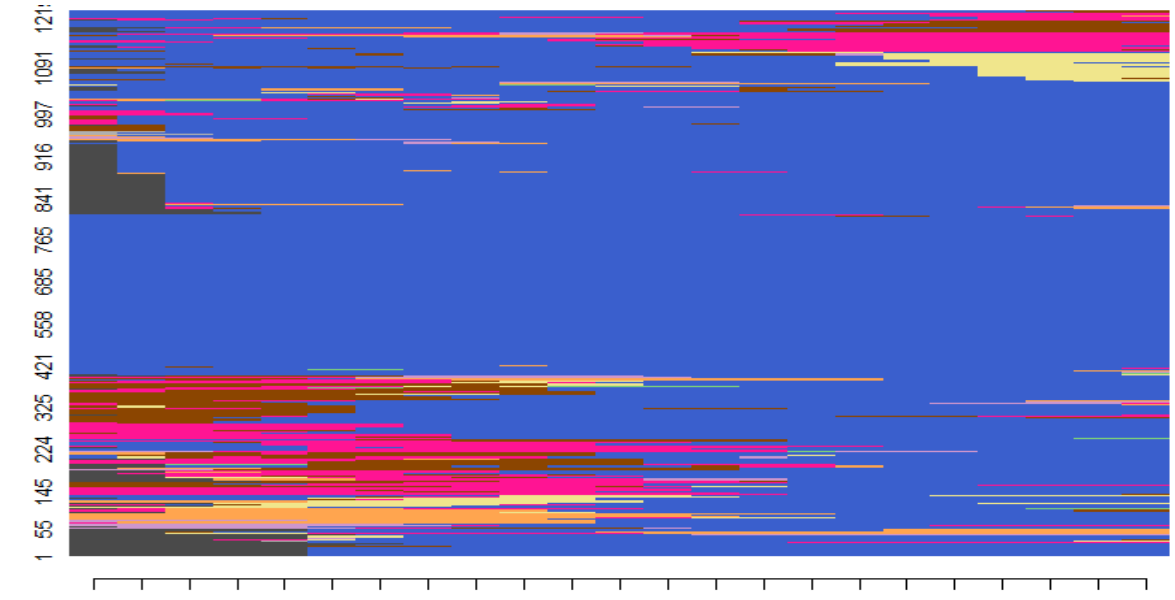

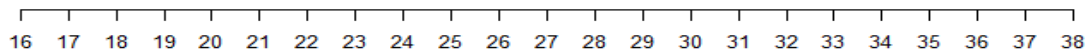

Type 8

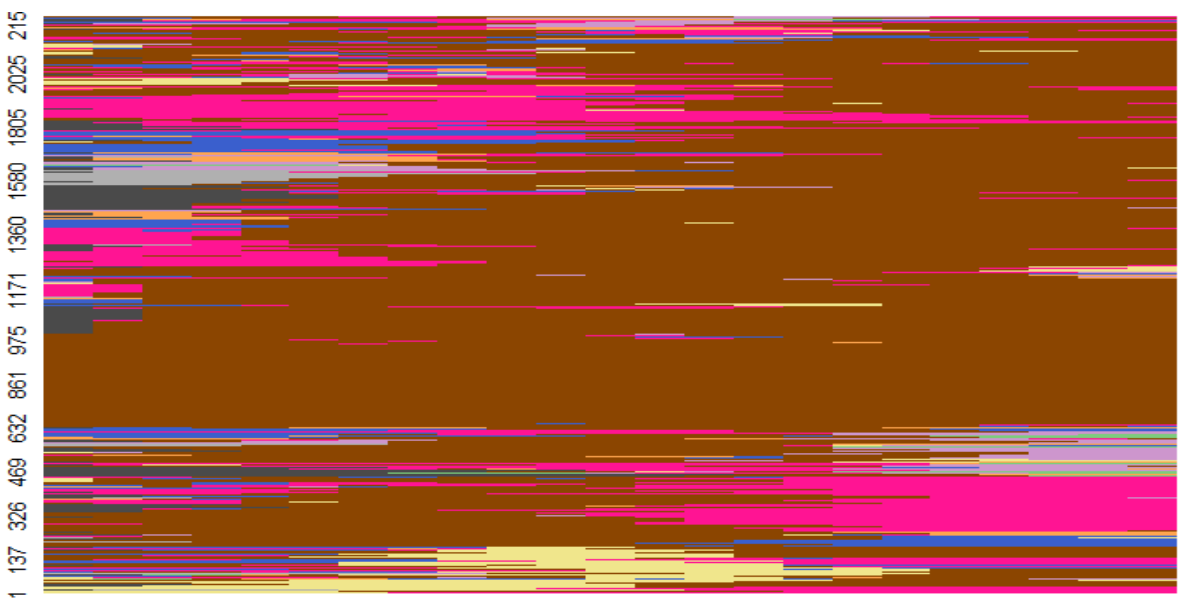

\begin{tabular}{llllllllllllllllllllllll}
\hline 16 & 17 & 18 & 1 & 1 & 1 & 1 & 1 & 1 & 1 & 1 & 1 & 1 & 1 & 1 & 1 & 1 & 1 & 1 & 1 & 1 & 1 \\
& 16 & 22 & 22 & 23 & 24 & 25 & 26 & 27 & 28 & 29 & 30 & 31 & 32 & 33 & 34 & 35 & 36 & 37 & 38
\end{tabular} 
Figure 2: Sequence index plots, women

Type 1

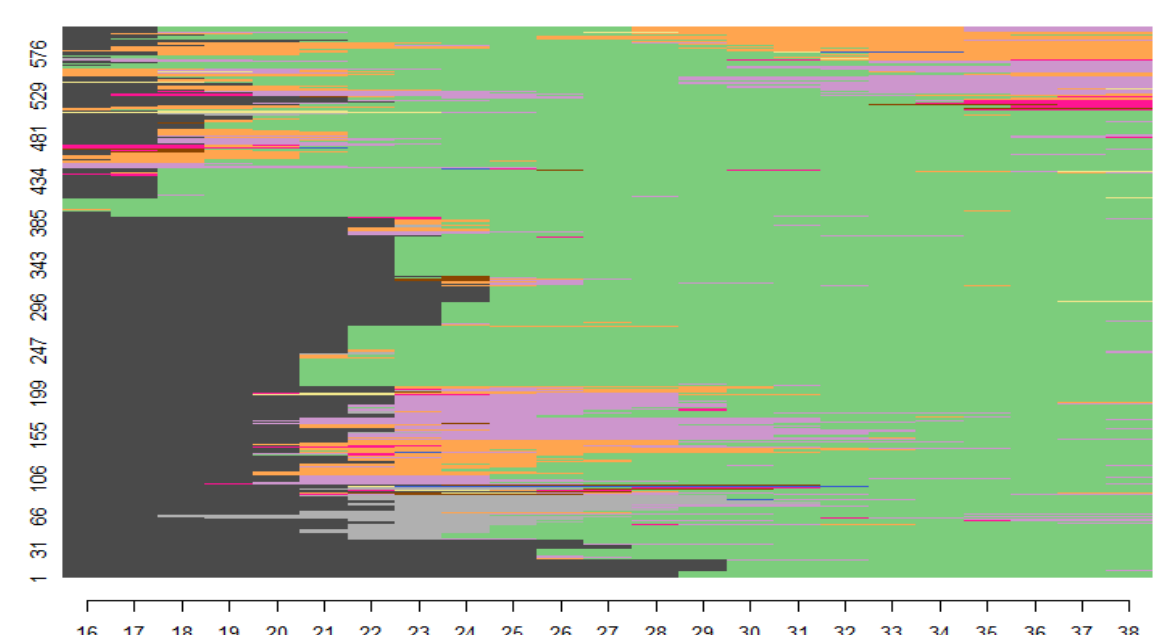

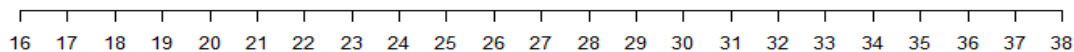

Type 3

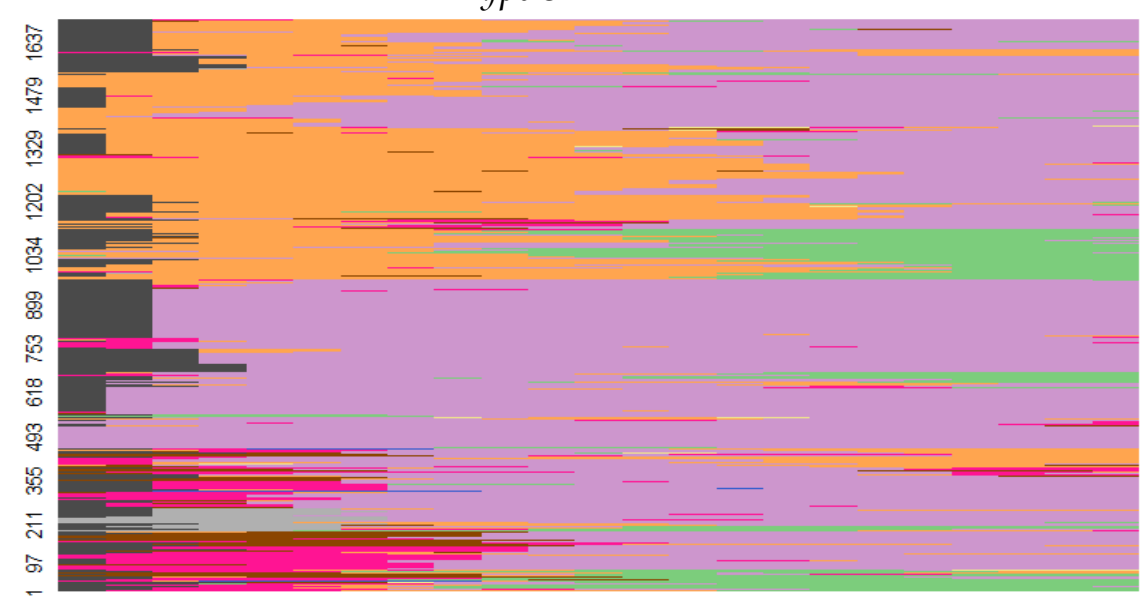

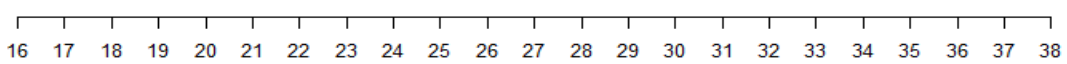

Type 2

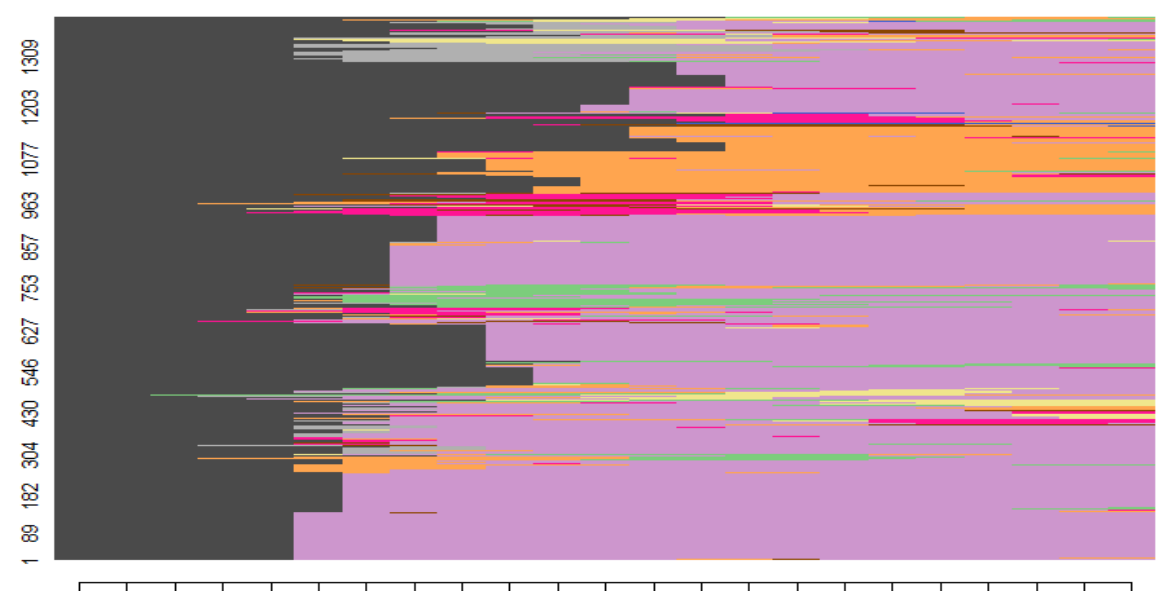

$\begin{array}{lllllllllllllllllllllll}16 & 17 & 1 & 19 & 1 & 1 & 1 & 1 & 1 & 1 & 1 & 1 & 1 & 1 & 1 & 1 & 1 & 1 & 1 & 1 & 1 & 1 \\ 16 & & 18 & & 21 & 22 & 23 & 24 & 25 & 26 & 27 & 28 & 29 & 30 & 31 & 32 & 33 & 34 & 35 & 36 & 37 & 38\end{array}$

Type 4

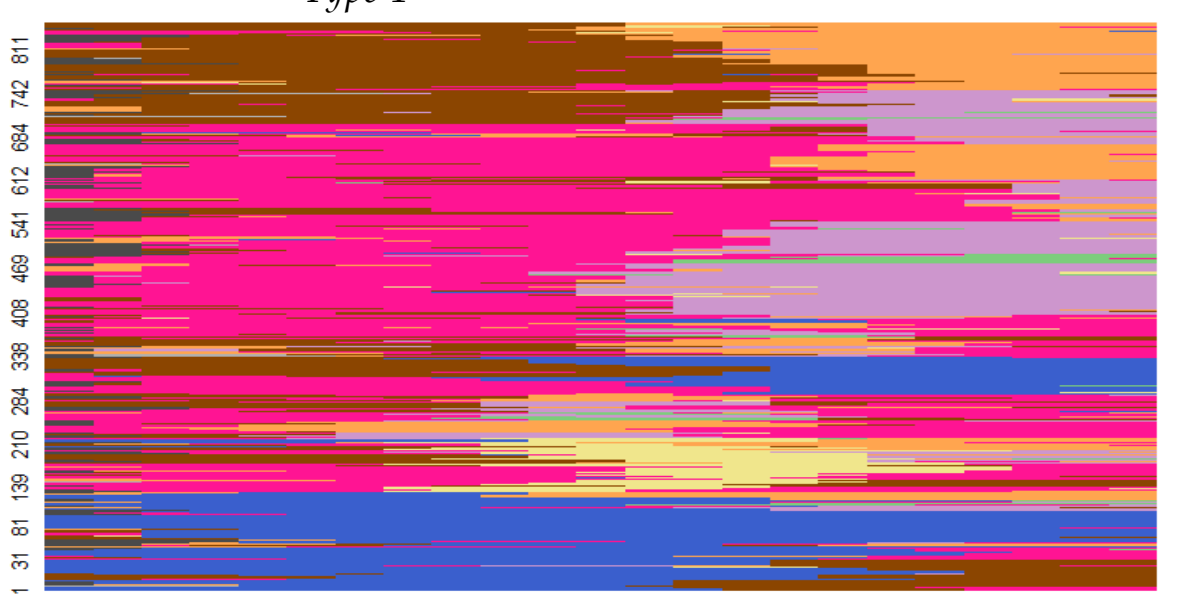

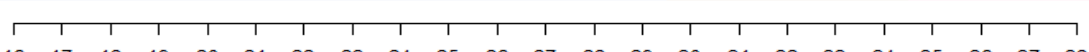


Figure 2: Sequence index plots, women (cont.)

Type 5

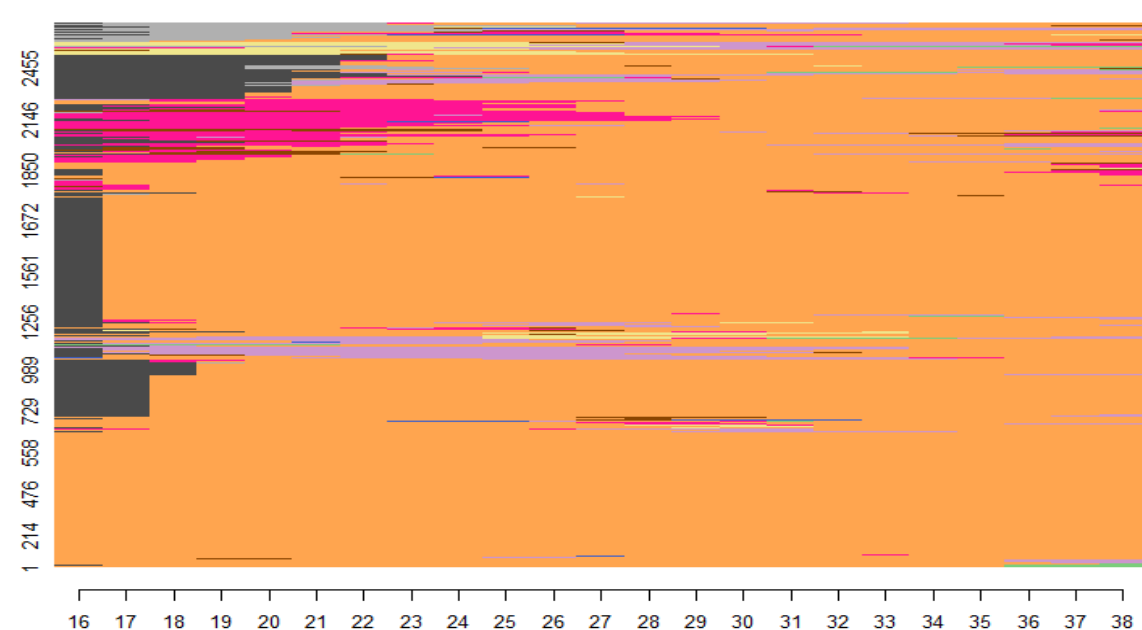

Type 7

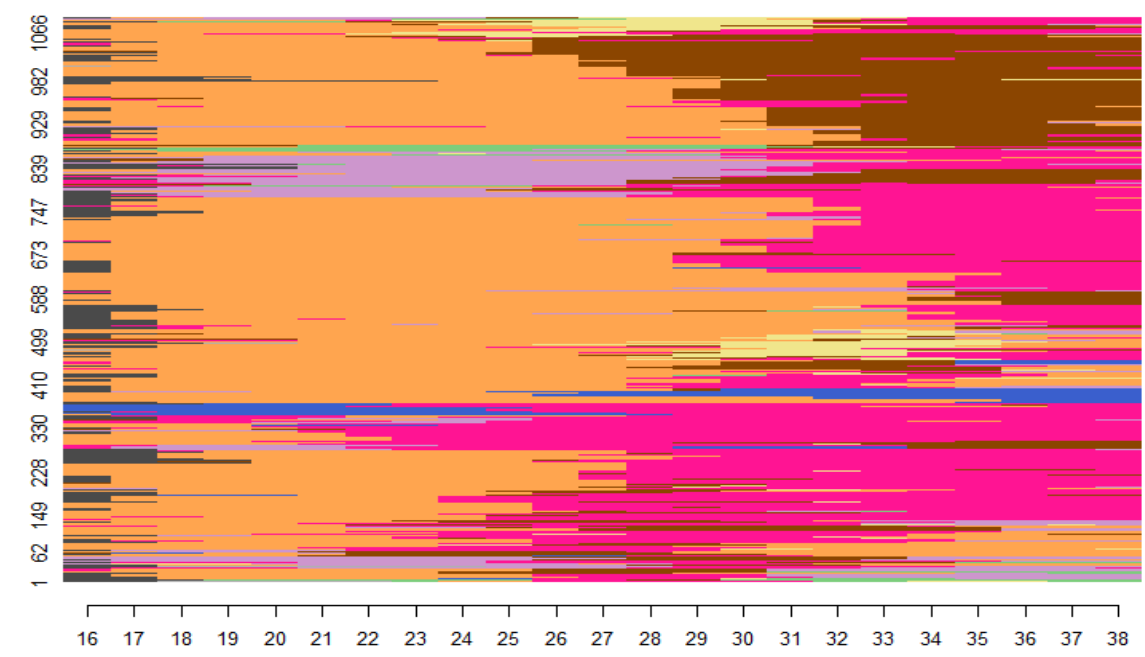

Type 6

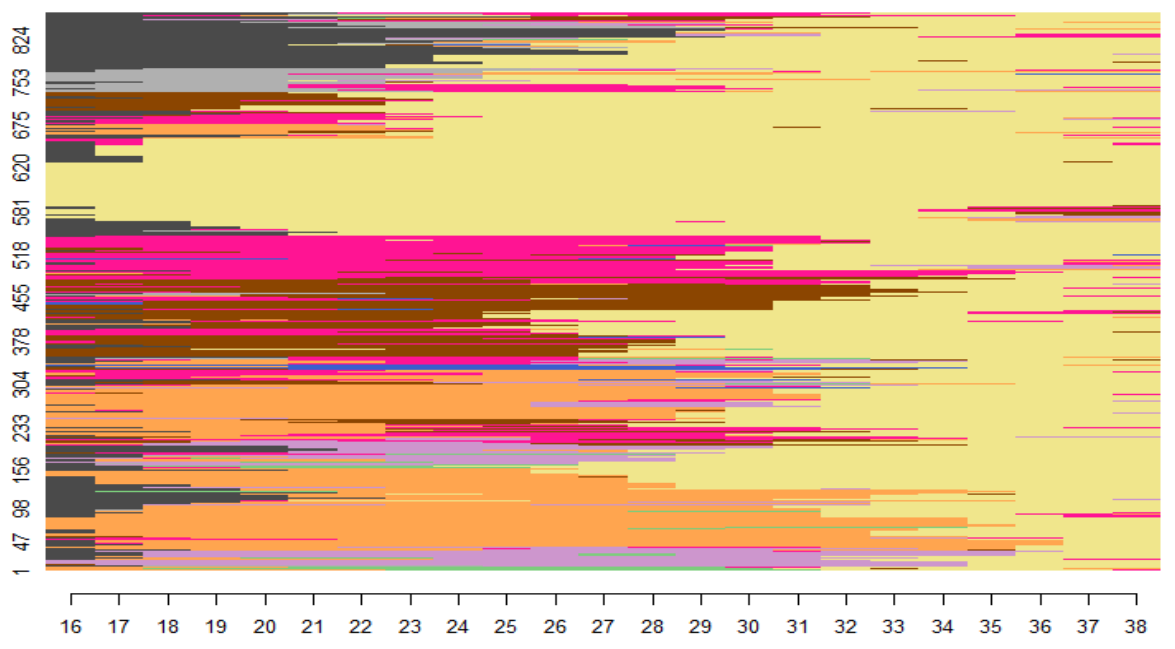

Type 8

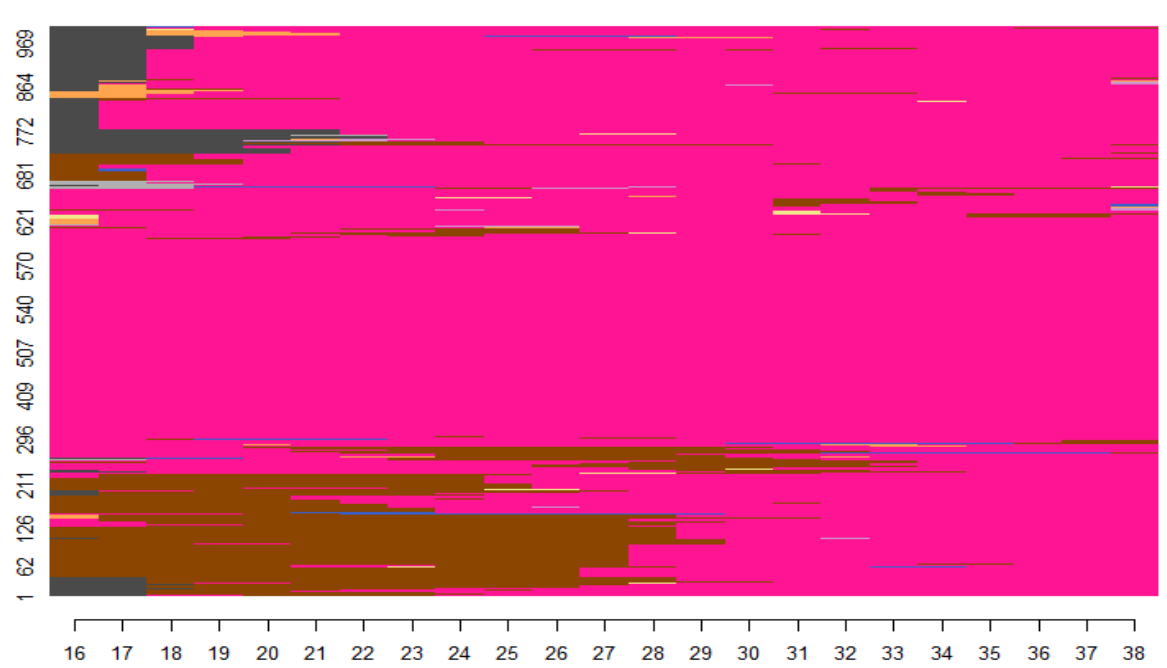


Figure 2: Sequence index plots, women (cont.)

Type 9

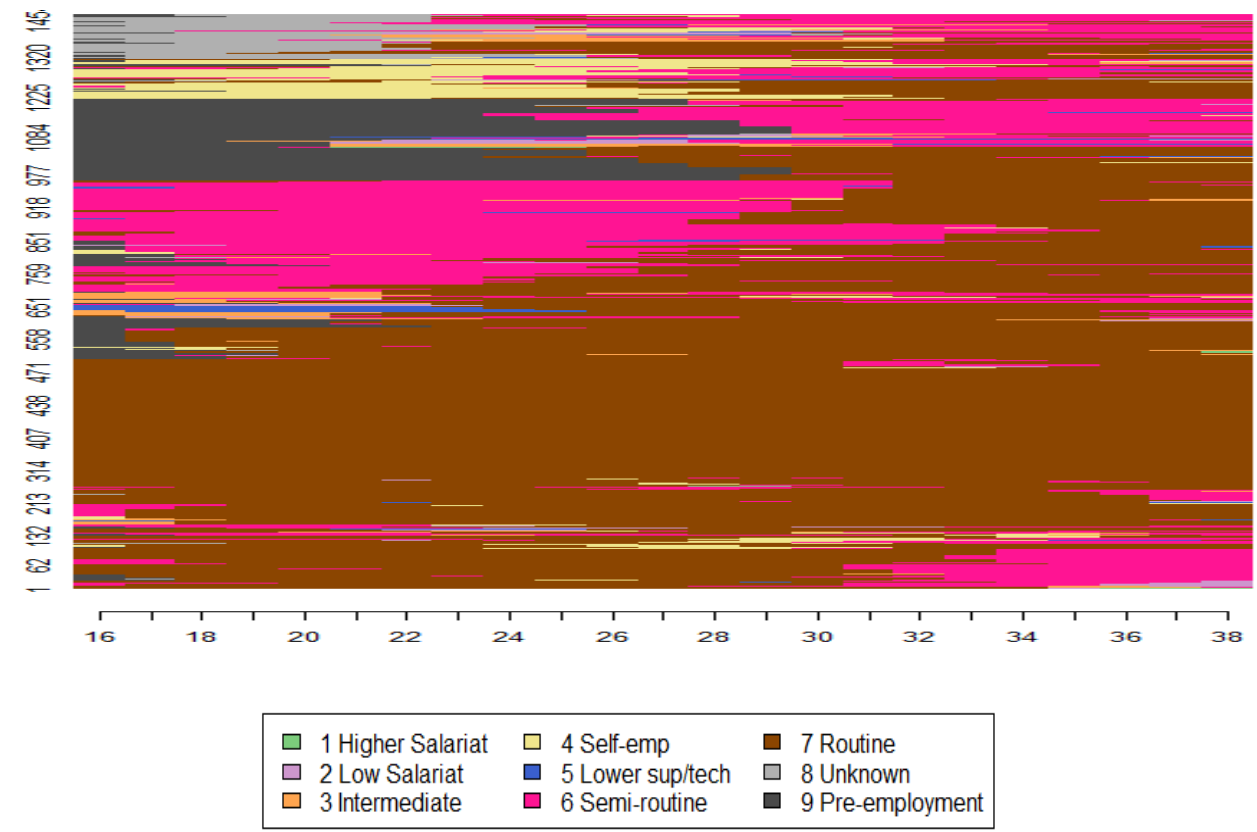


${ }^{1}$ A reviewer has questioned why we did not create separate states for being in professional as opposed to managerial employment. The answer is that, as noted in the Introduction, Bell clearly intends his argument to apply to both types of employment, and basing our analyses on NS-SEC, in which professionals and managers are, on the basis of well-established similarities in their employment relations, allocated to the same classes, would therefore seem appropriate. Claims that professionals and managers should be regarded as distinctive classes rely largely on 'arguing backwards' from differences of a subcultural and sociopolitical kind, which could in fact be better seen as reflecting differences in status and education.

${ }^{2}$ While procedures for the multiple imputation of missing data in life histories have been proposed (Halpin, 2012), we do not apply them in the present case. As noted, the extent of missing data varies across our cohorts but weighting them equally has little effect on the results of our sequence and cluster analyses (results available on request). When we take the class histories as a dependent variable, we do work with a dataset based on the multiple imputation of missing data for the independent variables. We use the MICE (Multiple Imputation using Chained Equations) package in Stata, and perform multiple imputation separately by cohort and gender, allowing for twenty sets of imputation. We then use Rubin's (1987) rules for combining these imputations. Average marginal effects are calculated using the procedure developed by Klein (2014).

${ }^{3}$ As indicated above, whether or not we weight our cohorts equally makes little difference to the results we achieve. However, we favour equal weighting in principle and in what 
follows report only results derived from data rescaled so that $\mathrm{N}=5,000$ for each cohort alike. A further issue that could be raised is that of how far, if we were to treat our three cohorts separately, we would obtain similar results for each. We have investigated this possibility and find that with both men and women differences across the cohorts are very small and insufficient to abandon the advantages of using the same typology for each cohort. 